\title{
Exploring individual cognitions, self-regulation skills, and environmental-level factors as mediating variables of two versions of a Web-based computer-tailored nutrition education intervention aimed at adults: $\mathrm{A}$ randomized controlled trial
}

Citation for published version (APA):

Springvloet, L., Lechner, L., Candel, M. J. J. M., de Vries, H., \& Oenema, A. (2016). Exploring individual cognitions, self-regulation skills, and environmental-level factors as mediating variables of two versions of a Web-based computer-tailored nutrition education intervention aimed at adults: A randomized controlled trial. Appetite, 98, 101-114. https://doi.org/10.1016/j.appet.2015.12.013

Document status and date:

Published: 01/03/2016

DOI:

10.1016/j.appet.2015.12.013

Document Version:

Publisher's PDF, also known as Version of record

Document license:

Taverne

Please check the document version of this publication:

- A submitted manuscript is the version of the article upon submission and before peer-review. There can be important differences between the submitted version and the official published version of record. People interested in the research are advised to contact the author for the final version of the publication, or visit the DOI to the publisher's website.

- The final author version and the galley proof are versions of the publication after peer review.

- The final published version features the final layout of the paper including the volume, issue and page numbers.

Link to publication

\footnotetext{
General rights rights.

- You may freely distribute the URL identifying the publication in the public portal. please follow below link for the End User Agreement:

www.umlib.nl/taverne-license

Take down policy

If you believe that this document breaches copyright please contact us at:

repository@maastrichtuniversity.nl

providing details and we will investigate your claim.
}

Copyright and moral rights for the publications made accessible in the public portal are retained by the authors and/or other copyright owners and it is a condition of accessing publications that users recognise and abide by the legal requirements associated with these

- Users may download and print one copy of any publication from the public portal for the purpose of private study or research.

- You may not further distribute the material or use it for any profit-making activity or commercial gain

If the publication is distributed under the terms of Article $25 \mathrm{fa}$ of the Dutch Copyright Act, indicated by the "Taverne" license above,

Download date: 26 Apr. 2023 


\title{
Exploring individual cognitions, self-regulation skills, and environmental-level factors as mediating variables of two versions of a Web-based computer-tailored nutrition education intervention aimed at adults: A randomized controlled trial
}

\author{
Linda Springvloet ${ }^{\mathrm{a},{ }^{*}, \text { Lilian Lechner }}{ }^{\mathrm{b}}$, Math J.J.M. Candel ${ }^{\mathrm{c}}$, Hein de Vries ${ }^{\mathrm{a}}$, Anke Oenema ${ }^{\mathrm{a}}$ \\ a Department of Health Promotion, School for Public Health and Primary Care (CAPHRI), Maastricht University, P.O. Box 616, 6200 MD Maastricht, The \\ Netherlands \\ ${ }^{\mathrm{b}}$ Faculty of Psychology and Educational Sciences, Open University of the Netherlands, PO Box 2960, 6401 DL Heerlen, The Netherlands \\ ${ }^{\mathrm{c}}$ Department of Methodology and Statistics, School for Public Health and Primary Care (CAPHRI), Maastricht University, P.O. Box 616, 6200 MD Maastricht, \\ The Netherlands
}

\section{A R T I C L E I N F O}

\section{Article history:}

Received 19 March 2015

Received in revised form

1 October 2015

Accepted 15 December 2015

Available online 19 December 2015

\section{Keywords:}

Computer tailoring

Mediation analysis

Environmental-level factors

Individual cognitions

Self-regulation

Nutrition education

\begin{abstract}
A B S T R A C T
Background: This study explored whether the determinants that were targeted in two versions of a Webbased computer-tailored nutrition education intervention mediated the effects on fruit, high-energy snack, and saturated fat intake among adults who did not comply with dietary guidelines.

Method: A RCT was conducted with a basic (tailored intervention targeting individual cognitions and self-regulation), plus (additionally targeting environmental-level factors), and control group (generic nutrition information). Participants were recruited from the general Dutch adult population and randomly assigned to one of the study groups. Online self-reported questionnaires assessed dietary intake and potential mediating variables (behavior-specific cognitions, action- and coping planning, environmental-level factors) at baseline and one (T1) and four (T2) months post-intervention (i.e. four and seven months after baseline). The joint-significance test was used to establish mediating variables at different time points (T1-mediating variables - T2-intake; T1-mediating variables - T1-intake; T2mediating variables - T2-intake). Educational differences were examined by testing interaction terms. Results: The effect of the plus version on fruit intake was mediated (T2-T2) by intention and fruit availability at home and for high-educated participants also by attitude. Among low/moderate-educated participants, high-energy snack availability at home mediated (T1-T1) the effect of the basic version on high-energy snack intake. Subjective norm mediated (T1-T1) the effect of the basic version on fat intake among high-educated participants.

Discussion: Only some of the targeted determinants mediated the effects of both intervention versions on fruit, high-energy snack, and saturated fat intake. A possible reason for not finding a more pronounced pattern of mediating variables is that the educational content was tailored to individual characteristics and that participants only received feedback for relevant and not for all assessed mediating variables.

Trial registration: Netherlands Trial Registry NTR3396.
\end{abstract}

๑) 2015 Published by Elsevier Ltd.

\footnotetext{
* Corresponding author.

E-mail addresses: linda.springvloet@maastrichtuniversity.nl (L. Springvloet), lilian.lechner@ou.nl (L. Lechner), math.candel@maastrichtuniversity.nl (M.J.J.M. Candel), hein.devries@maastrichtuniversity.nl (H. de Vries), a.oenema@ maastrichtuniversity.nl (A. Oenema).
}

\section{Introduction}

Computer-tailored nutrition education interventions have been shown to be effective in changing self-reported dietary behavior (Broekhuizen, Kroeze, van Poppel, Oenema, \& Brug, 2012; Krebs, Prochaska, \& Rossi, 2010; Kroeze, Werkman, \& Brug, 2006; Neville, O'Hara, \& Milat, 2009), among both higher- and lower- 
educated individuals (Brug \& van Assema, 2000; Noar, Benac, \& Harris, 2007). The pathways through which effects of such interventions are generated are, however, largely unknown. Identifying factors that contribute to the intervention effects provides insight into the most important determinants (i.e. factors that influence the behavior, such as attitude) needed to generate an intervention effect. Such variables are referred to as mediating variables. Targeting the most important mediating variables and omitting or adapting non-mediating determinants may make interventions more (cost-)efficient, without compromising efficacy (Hafeman \& Schwarz, 2009). In addition, by examining educational differences in mediating variables, interventions can be made more efficient and effective for different educational groups. Creating effective interventions is especially important for lower-educated individuals, because they are more likely to engage in dietary risk behaviors (Ball, Crawford, \& Mishra, 2006; Inglis, Ball, \& Crawford, 2008; Konttinen, Sarlio-Lähteenkorva, Silventoinen, Männistö, \& Haukkala, 2012; van Rossum, Fransen, Verkaik-Kloosterman, Buurma-Rethans, \& Ocké, 2011).

The aim of the present study was to explore the mediating variables of the effects of two versions (basic and plus) of a previously evaluated Web-based computer-tailored nutrition education intervention (Springvloet, Lechner, \& Oenema, 2014) among adults who did not comply with the dietary guidelines. A second aim was to explore potential educational differences in mediating variables. Both intervention versions targeted individual cognitions and selfregulation; the plus version additionally targeted environmentallevel factors. An effect evaluation of the intervention showed that the basic version was effective in decreasing saturated fat intake and the plus version was effective in increasing fruit intake among people who did not comply with dietary guidelines at baseline (Springvloet, Lechner, de Vries, Candel, \& Oenema, 2015). For highenergy snack intake, among high-educated participants both versions were effective at short term, but at medium term only the basic version was effective; among lower-educated participants only the basic version was effective at both short and medium term. In the current study we explored which variables have contributed to these intervention effects (i.e. through which variables the intervention effects were mediated).

Only a few previous studies on computer-tailored nutrition education interventions have examined whether the effects on dietary behavior were mediated by the determinants that are included in this intervention (Anderson, Winett, Wojcik, Winett, \& Bowden, 2001; Broekhuizen et al., 2012; Lustria, Cortese, Noar, \& Glueckauf, 2009; Luszczynska, Tryburcy, \& Schwarzer, 2007; Winett, Anderson, Wojcik, Winett, \& Bowden, 2007). However, these studies did not always identify mediating variables; changes were found in some determinants only or in no determinant at all. Targeting environmental-level factors as was done in the current intervention is a novelty for Web-based computer-tailored nutrition education interventions and no mediation through these factors has been established yet. For physical activity, however, a previous study among older adults showed that changes in perceptions of the environment mediated the effects on physical activity of a print-delivered computer-tailored intervention (i.e. assessment questionnaire and feedback delivered to the participants on paper) that provided objective environmental-level information (van Stralen, de Vries, Mudde, Bolman, \& Lechner, 2009). Further, no previous studies that examined educational differences in mediating variables are known.

The aim of the present study was to explore whether the shortterm (one month post-intervention; i.e. four months post-baseline, as the intervention period started one month after baseline and lasted for two months) and medium-term (four months postintervention, which is seven months post-baseline) intervention effects on fruit, high-energy snack, and saturated fat intake were mediated by the individual cognitions, self-regulation skills, and environmental-level factors that were targeted in the intervention. An additional aim was to explore potential educational differences in the mediating variables. The mediating variables were explored among participants who at baseline did not comply with dietary guidelines, because these risk groups should specifically benefit from the intervention. It was hypothesized that both intervention versions exerted their effects via changes in individual cognitions (awareness, attitude, self-efficacy, and intention) and action- and coping planning. Because only the plus version targeted environmental-level factors, it was expected that the availability and location of food products at home and the perception of availability and price of healthy food products in the supermarket would mediate the effects of the plus version only.

\section{Material and methods}

A detailed overview of the study protocol has been described elsewhere (Springvloet et al., 2014). Therefore, a summary of the methodology and protocol is described below. The trial is registered in the Dutch Trial Registry (NTR339) and was approved by the Medical Ethics Committee of the Erasmus Medical Centre in Rotterdam (NL35430.078.11/MEC-2010-408).

\subsection{Study design and study procedure}

A three-group RCT was conducted from March 2012 to December 2013 in the Netherlands. The entire study was conducted online and all outcomes were self-reported. The target group for this trial were adults, aged 20-65 years. Participants were recruited between March and October 2012 from the general population in five cities in the South of the Netherlands. Personal mailings were sent to 26,402 random home addresses that were obtained via municipalities. Additionally, Facebook advertisements, advertisements in (local) newspapers, local television, and promotion activities in shopping malls (i.e. distribution of flyers and talking to people) were used for recruitment. People received an information folder with information about the procedure and incentives for the study. People could sign up for participation by phone, e-mail, or via the study website. Inclusion criteria were: being aged between 20 and 65 years, having a sufficient understanding of the Dutch language (in reading and writing) and having Internet access. Exclusion criteria were: being on a diet prescribed by a physician or dietician, having a medical condition that implies restrictions in eating behavior, and not willing to sign a written informed consent form.

After signing up for the study, a link to an online baseline questionnaire was sent via e-mail. The baseline questionnaire first assessed the inclusion- and exclusion criteria. People who met the inclusion criteria were asked to give online informed consent before they could continue with the baseline questionnaire. Additionally, a written informed consent form was sent via postal- or email and only people who signed and returned this form were included in the study.

One month after completing the baseline questionnaire participants could start to use the intervention program. Participants were individually randomized to the basic intervention group ( $n=456)$, the plus intervention group $(n=459)$, or the control group (receiving generic nutrition information; $n=434$ ) in a computer-determined sequence. Participants received a login code and password through e-mail, which gave them access to the allocated intervention program on the study website. Because the intervention consisted of three sessions, participants were asked to visit and work through the content of the website at least three 
times during a two-month period. E-mail reminders to (re-)visit the intervention were sent every two weeks. One and four months after the intervention period (four and seven months after the baseline questionnaire, respectively), participants were invited by e-mail to fill out online questionnaires again. Among participants who completed all questionnaires of the study, 20 iPad's and 500 gift vouchers of 20 euro's were allotted. To improve follow-up response, one extra iPad and 25 extra gift vouchers were allotted. The study-flow, selection, and enrolment of participants and the measurements for each of the three risk groups (i.e. fruit, snacks, and fat) are shown in Fig. 1.

\subsection{Intervention}

\subsubsection{Basic and plus version of the intervention}

Both intervention versions are described briefly below, but a more detailed description is published elsewhere (Springvloet et al., 2014). The aim of the two versions of the intervention was to increase fruit and vegetable intake and decrease high-energy snack and saturated fat intake. Both versions were developed in a systematic way using the Intervention Mapping protocol (Bartholomew, Parcel, Kok, Gottlieb, \& Fernández, 2011) and were partly based on existing interventions (Kroeze, Oenema, Campbell, \& Brug, 2008; Oenema, Tan, \& Brug, 2005). Both versions consisted of four modules (i.e. fruit, vegetables, high-energy snacks, and fat), each containing three sessions that could be worked through during preferably six consecutive weeks. In general, the first session took approximately 20-30 min to complete per module; the second and third sessions took approximately 10-20 min per module. Participants were free in choosing how long they wanted to use the website and could leave the intervention at any time.

Both versions were based on Self-Regulation Theory (Maes \& Karoly, 2005), the Theory of Planned Behavior (Ajzen, 1991), and the Precaution Adoption Process Model (Weinstein, Sandman, \& Blalock, 2008) and targeted knowledge, awareness, attitude, selfefficacy, intention, goal setting, and action- and coping planning, by means of appropriate behavior change strategies (Abraham \& Michie, 2008; Bartholomew et al., 2011; Gollwitzer \& Sheeran, 2006; Kok, Lechner, Meertens, \& Brug, 2012; Mento, Steel, \& Karren, 1987; Michie, Abraham, Whittington, McAteer, \& Gupta, 2009; Neubert, 1998; Sniehotta, Schwarzer, Scholz, \& Schüz, 2005; Strecher et al., 1995; Weinstein, 1988). All four modules had a similar structure, except for the fat module that did not contain methods to target attitude and self-efficacy. This was done to limit participant burden, because the assessment of saturated fat intake was quite long. The three sessions of each module were arranged according to the phases that are distinguished in selfregulation: pre-action, action, and evaluation (Karoly, 1993; Maes \& Gebhardt, 2000).

The first session of each module started with information on the self-chosen behavior to increase knowledge about the target behavior. Subsequently, participants could assess their behavior, based on which tailored feedback was provided to increase awareness. Attitude was targeted by providing feedback on selfselected advantages and disadvantages. Feedback on self-selected potential barriers and difficult situations was provided to increase self-efficacy. At the end of the first session participants could set a behavioral goal and formulate an implementation intention (i.e. an if-then statement) for each targeted behavior.

The second and third session provided the opportunity to

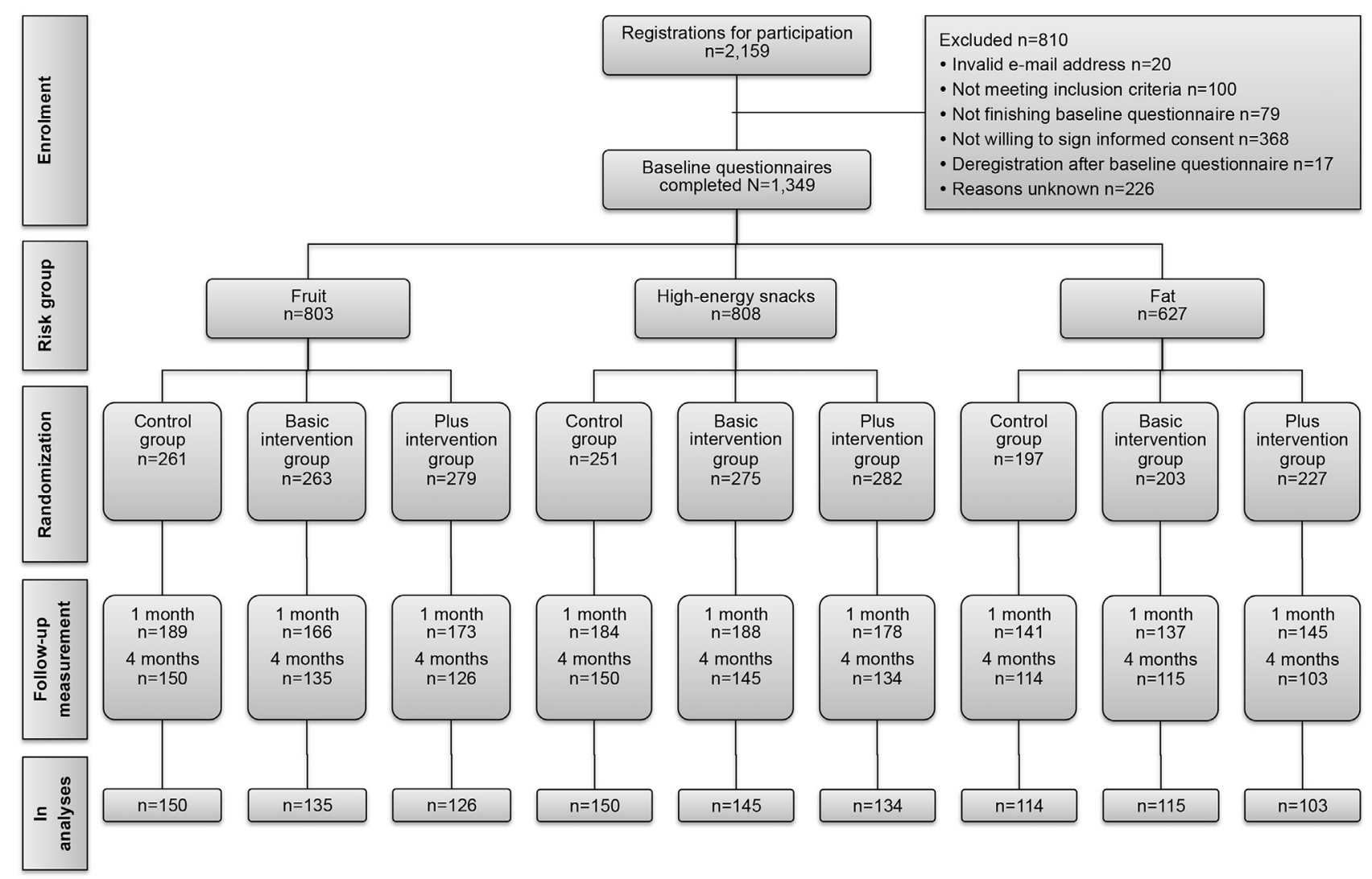

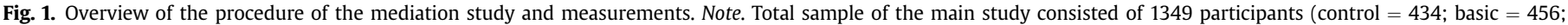

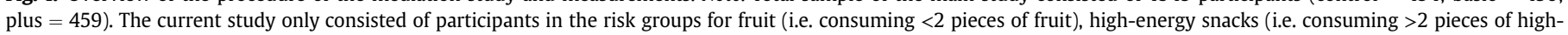
energy snacks), and saturated fat intake (i.e. not complying with age- and gender-specific guidelines for saturated fat). 
evaluate the progress of the behavior change. Participants first monitored their goal achievement and behavior in the past week and were provided with feedback on their progression towards goal achievement. When the goal had not been achieved, attitude and self-efficacy were targeted to stimulate participants to take a second attempt. In addition, all participants could formulate coping plans for expected difficult situations. If necessary, goals could be adapted to make them more achievable or more challenging. The third session additionally provided information on how to maintain the behavior change over time, based on the three self-regulation phases.

\subsubsection{Plus version of the intervention}

The content of the plus version was identical to the basic version, but the first session additionally included environmentallevel feedback on the availability and prices of healthy food products in the supermarket the participant usually does his or her shopping and on the availability and location of food products in the home food environment. The second and third sessions were identical to the basic version. The feedback on the availability and price of food products in the supermarket where the participant buys their food products (e.g. fruit) was incorporated in the feedback on attitude and self-efficacy. After selecting relevant disadvantages or barriers (e.g. 'fruit is expensive'), participants received objective environmental-level information, presented as a list of selected food products that are available in the supermarket, with the price of the products if relevant for the disadvantage or barrier. This environmental-level feedback was also provided in a separate section before the section in which participants could state a goal and action plan. In addition, the arrangement of the home food environment was targeted. Participants could fill out whether they always have fruit or high-energy snacks available at home and where they store fruit or high-energy snacks. Subsequently, participants received feedback on possible improvements in availability and storage of products (e.g. 'make sure you always have fruit available and store the fruit in a visible place, like in a fruit bowl'). Fig. 2 provides an overview of both the basic and plus intervention version.

\subsubsection{Control condition}

The generic information for the control condition also consisted of four modules, each consisting of three sessions that could be worked through in six consecutive weeks. Participants could choose for which behavior(s) they wanted to have information and received non-tailored information about fruit, vegetables, highenergy snacks, and/or saturated fat (GroentenFruit Bureau (Dutch Vegetable and Fruit Bureau); Voedingscentrum (Netherlands Nutrition Centre)). Information was provided about, amongst others, the importance of complying with guidelines, how people can eat more fruit, and how people can maintain eating fewer highenergy snacks. The control program had the same name and was provided via the same website and in the same layout as the two intervention versions.

\subsection{Measures}

Self-reported data on fruit, high-energy snack, and saturated fat intake and potential mediating variables were assessed with online questionnaires at baseline (T0) and one month (T1; four months post-baseline) and four months post-intervention (T2; seven months post-baseline). The trial and intervention also targeted vegetable intake, but this dietary behavior was not included in the present study, because no intervention effects were found for vegetable intake.

\subsubsection{Dietary outcomes}

Fruit intake was measured with a validated food frequency questionnaire (FFQ) using six items (Bogers, van Assema, Kester, Westerterp, \& Dagnelie, 2004; van Assema, Brug, Ronda, Steenhuis, \& Oenema, 2002). Participants were asked on how many days per week they usually consume citrus fruit, other fruit or (unsweetened) fruit juices (ranging from 0 to 7 days per week) and how many pieces or glasses they usually consume of citrus fruit, other fruit or fruit juices on these days (one to seven or more). The intake of pieces of fruit per day was calculated by multiplying the frequency by the number of pieces, divided by seven (days a week).

Saturated fat intake was measured with a validated FFQ (the "fat list') aimed to assess the frequency and quantity of a variety of food items eaten in the past week (van Assema, Brug, Ronda, \& Steenhuis, 2001). Participants were asked on how many days per week they usually consume a selection of food items during or between meals. If applicable, the quantity and kind of products (e.g. low-fat or full-fat milk) were also assessed. Based on this questionnaire fat points were calculated, which represent grams of (saturated) fat. The total 'fat score' was based on 35 questions, assessing food products in the following categories: dairy products ( $n=11)$, butter $(n=1)$, gravy $(n=3)$, sandwich fillings $(n=6)$, meat and cheese eaten at dinner $(n=4)$ and snacks $(n=10)$. Based on the frequency, quantity, and kind of product, fat points were calculated for each product group, ranging from 0 (lowest fat intake) to a maximum of two to five (highest fat intake, depending on how much fat a product group contains). The fat points for each product group were summed up to create a total fat point measure. In total, a maximum of 80 fat points could be obtained.

To measure snack intake, questions about frequency of highenergy snack intake from the 'fat list' questionnaire (van Assema et al., 2001) were used, in combination with extra items added to measure the number of snacks eaten per occasion. A total of 21 items measured high-energy snack intake, such as fried products, candy bars, cookies, and chocolate. High-energy snack intake was calculated as the mean number of high-energy snacks eaten per day, by multiplying the frequency per week by the quantity eaten per occasion, dividing by seven (days a week).

\subsubsection{Definition of risk groups}

Only participants who did not comply with at least one of the dietary guidelines were included in the analyses. The analyses were conducted for each dietary outcome separately and, consequently, participants could be present in more than one risk group (e.g. not complying with fruit intake and not complying with saturated fat intake). In line with the Dutch dietary guidelines (Voedingscentrum (Netherlands Nutrition Centre), 2011) for fruit intake, the participants who consumed $<2$ pieces were categorized as not complying with the guideline. Participants who consumed $>2$ pieces of high-energy snacks per day were considered as not complying with the guidelines for high-energy snack intake. The cut-off points for not complying with the guidelines for saturated fat intake depended on age and gender and ranged from 16 to 21 fat points.

\subsubsection{Potential mediating variables}

All potential mediating variables were measured for each dietary outcome separately (Table 1). Perceived intake was measured by asking whether participants perceived their fruit, high-energy snack, and fat intake as high or low (5-point scale). Subsequently, a dichotomous variable of awareness was created by linking the perceived intake with the actual intake as assessed with the FFQ. Participants who overestimated their fruit intake or underestimated their snack or fat intake were unaware of their actual intake and were coded 0 for the dietary-specific awareness 


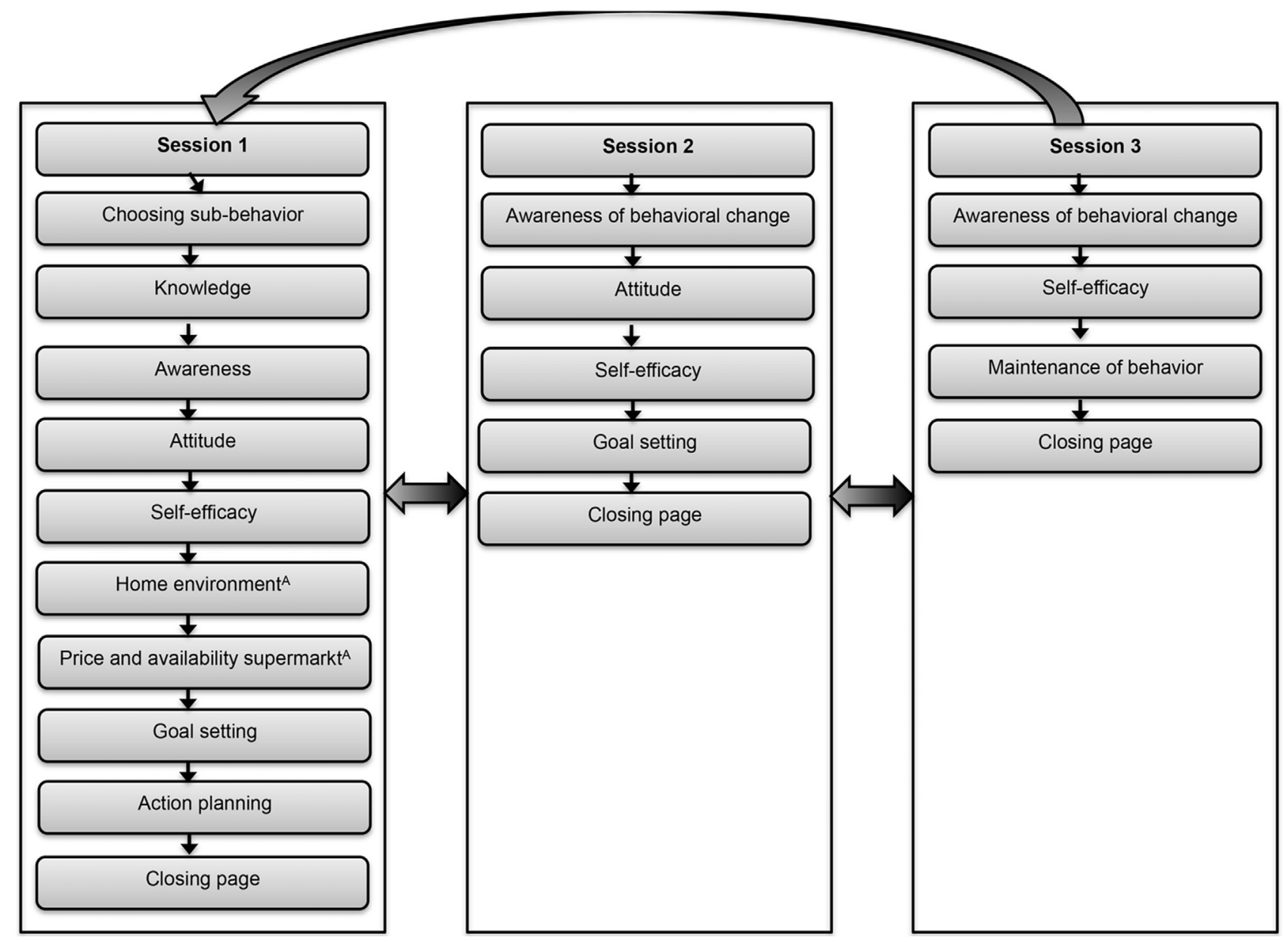

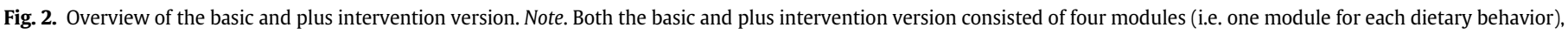

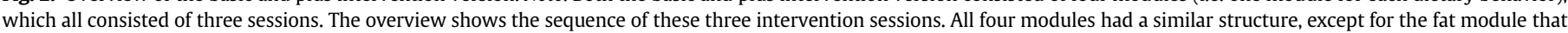

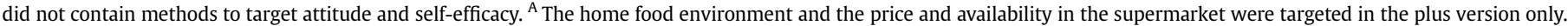

variable. Others were coded as one for the dietary-specific awareness variable. Attitude towards consuming fewer high-energy snacks and less fat was measured with two items that assessed health and importance beliefs. Attitude towards consuming two pieces of fruit per day additionally included an item about taste. For high-energy snack and fat intake, this attitude item was analyzed separately, because it did not fit into the attitude scale. The perception of fruit, lower-energy snacks, and low-fat products as being expensive was measured with one item per dietary outcome, which did not fit into the attitude scale and was therefore included in the analyses as a separate item. Self-efficacy expectations were measured with two items about perceived difficulty and ability of consuming two pieces of fruit a day, fewer high-energy snacks or less fat. Social influence was assessed with one item relating to subjective norm and one item relating to perceived intake of others (modeling). Intention was assessed with one item that measured whether the participant intended to consume two pieces of fruit a day, fewer high-energy snacks or less fat. The individual cognitions (Ajzen, 1991) were derived from questionnaires that have been successfully used in previous studies and were measured on a 5point scale.

Action planning was assessed with three items that measured whether participants had a clear plan for when, how much, and which fruit to eat more or high-energy snacks to eat less (Sniehotta et al., 2005). Coping planning (Sniehotta et al., 2005) was measured by assessing whether participants had clear plans for what to do in difficult situations and when something interferes with their plans. Action- and coping planning were measured on a 4-point scale, ranging from completely disagree to completely agree. Action- and coping planning were not measured for fat intake. The action- and coping planning items were derived from a previously developed questionnaire (Sniehotta et al., 2005).

The perception of the availability of fruit, lower-energy snacks, and low-fat products in the supermarket where someone usually does his or her shopping was measured by assessing whether participants perceived the availability of the specific food product in their supermarket as insufficient or sufficient (5-point scale). The availability and location of fruit, high-energy snacks, and high-fat products at home were assessed by questions on how often participants had the specific food product available at home (5-point scale) and whether participants stored these products in a visible or invisible place (dichotomous). The items on the environmentallevel factors were newly developed for this study and no information on reliability and validity is available.

If the internal consistency of a scale was sufficient (i.e. Cronbach's alpha $>0.70$ (George \& Mallery, 2005)), a composite measure was created (Table 1). Otherwise, the items were used separately.

\subsubsection{Demographic factors}

Gender (male vs. female), age (in years), place of residence ('What is your place of residence?'; answer categories: Heerlen, Roermond, Weert, Venlo, Venray), ethnicity, and educational level 
Table 1

Assessment of potential mediating variables. ${ }^{a}$

\begin{tabular}{|c|c|c|c|}
\hline Concept & Items & Answer categories & $\alpha$ At baseline \\
\hline \multicolumn{4}{|c|}{ Individual cognitions } \\
\hline Awareness & How many fruit/high-energy snacks/fat do you think you eat? & A lot (1) - Only a few (5) & N.A. \\
\hline \multirow[t]{3}{*}{ Attitude ${ }^{\mathrm{b}}$} & \multirow[t]{3}{*}{ I think eating two pieces of fruit/fewer high-energy snacks/less fat per day is ... } & $\begin{array}{l}\text { Very unhealthy (1) - very } \\
\text { healthy (5) }\end{array}$ & Fruit: 0.70 \\
\hline & & $\begin{array}{l}\text { Very unimportant (1) - very } \\
\text { important (5) }\end{array}$ & $\begin{array}{l}\text { High-energy snacks: } 0.24 \\
\text { (without taste: } 0.70 \text { ) }\end{array}$ \\
\hline & & $\begin{array}{l}\text { Very disgusting ( } 1) \text { - very } \\
\text { delicious }(5)\end{array}$ & $\begin{array}{l}\text { Fat: } 0.62 \text { (without taste: } \\
0.81 \text { ) }\end{array}$ \\
\hline $\begin{array}{l}\text { Attitude - } \\
\text { price }^{\mathrm{b}, \mathrm{c}}\end{array}$ & I think eating two pieces of fruit/fewer high-energy snacks/less fat per day is ... & $\begin{array}{l}\text { Very expensive (1) - very } \\
\text { cheap (5) }\end{array}$ & N.A. \\
\hline \multirow[t]{2}{*}{ Self-efficacy ${ }^{\mathrm{b}}$} & $\begin{array}{l}\text { Do you think you can eat more fruit/fewer high-energy snacks/less fat per day in the next } \\
\text { six months if you really want to? }\end{array}$ & $\begin{array}{l}\text { Definitely not (1) - definitely } \\
\text { (5) }\end{array}$ & $\begin{array}{l}\text { Fruit: } 0.83 \\
\text { High-energy snacks: } 0.51 \\
\text { Fat: } 0.45\end{array}$ \\
\hline & $\begin{array}{l}\text { How difficult or easy do you think it is to eat more fruit/fewer high-energy snacks/less fat } \\
\text { in the next six months? }\end{array}$ & $\begin{array}{l}\text { Very difficult (1) - very easy } \\
\text { (5) }\end{array}$ & \\
\hline \multirow[t]{2}{*}{$\begin{array}{l}\text { Social } \\
\text { influence }^{\text {b }}\end{array}$} & \multirow{2}{*}{$\begin{array}{l}\text { Most people who are important to me think I should eat two pieces of fruit/fewer high- } \\
\text { energy snacks/less fat per day (subjective norm) } \\
\text { Most people who are important to me consume two pieces of fruit per day/few high- } \\
\text { energy snacks/not too many fat per day (modeling) }\end{array}$} & \multirow[t]{2}{*}{$\begin{array}{l}\text { Definitely not (1) - definitely } \\
\text { (5) }\end{array}$} & $\begin{array}{l}\text { Fruit: } 0.73 \\
\text { High-energy snacks: } 0.32\end{array}$ \\
\hline & & & Fat: 0.15 \\
\hline Intention ${ }^{\mathrm{b}}$ & Do you intend to eat two pieces of fruit/fewer high-energy snacks/less fat per day? & $\begin{array}{l}\text { Definitely not (1) - definitely } \\
\text { (5) }\end{array}$ & N.A. \\
\hline \multicolumn{4}{|c|}{ Self-regulation skills } \\
\hline \multirow{3}{*}{$\begin{array}{l}\text { Action } \\
\text { planning }\end{array}$} & \multicolumn{3}{|l|}{ I have a clear plan for .... } \\
\hline & ... when I am going to eat more fruit/fewer high-energy snacks & Completely disagree (1) - & Fruit: 0.91 \\
\hline & $\begin{array}{l}\text {... which fruit/high-energy snacks I am going to eat more/less } \\
\ldots \text { how many fruit/high-energy snacks I am going to eat more/less }\end{array}$ & completely agree (4) & High-energy snacks: 0.96 \\
\hline \multirow{2}{*}{$\begin{array}{l}\text { Coping } \\
\text { planningd,e }\end{array}$} & I have a clear plan for what I am going to do ... & & \\
\hline & $\begin{array}{l}\ldots \text { when something interferes with my plans to eat more fruit/fewer high-energy snacks } \\
\ldots \text { in situations in which it is difficult to eat more fruit/fewer high-energy snacks }\end{array}$ & $\begin{array}{l}\text { Completely disagree (1) - } \\
\text { completely agree (4) }\end{array}$ & $\begin{array}{l}\text { Fruit: } 0.96 \\
\text { High-energy snacks: } 0.96\end{array}$ \\
\hline \multicolumn{4}{|c|}{ Environmental-level factors } \\
\hline $\begin{array}{l}\text { Perception of } \\
\text { availability }^{\mathrm{b}}\end{array}$ & $\begin{array}{l}\text { In the store where I usually do my shopping, there is a sufficient amount of fruit/lower- } \\
\text { energy snacks/low-fat products available }\end{array}$ & $\begin{array}{l}\text { Completely disagree (1) - } \\
\text { completely agree }(5)\end{array}$ & N.A. \\
\hline $\begin{array}{l}\text { Availability at } \\
\text { home }^{\text {b }}\end{array}$ & How often do you have fruit/high-energy snacks/high-fat products available at home? & Never (1) - always $(5)^{\mathrm{f}}$ & N.A. \\
\hline $\begin{array}{l}\text { Location at } \\
\text { home }\end{array}$ & Where do you store the fruit/high-energy snacks/high-fat products at home? & \multicolumn{2}{|c|}{$\begin{array}{l}\text { On an invisible place }(1) \text { - On a N.A. } \\
\text { visible place }(2)^{\mathrm{f}}\end{array}$} \\
\hline
\end{tabular}

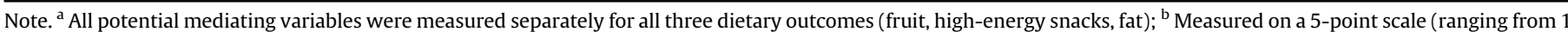

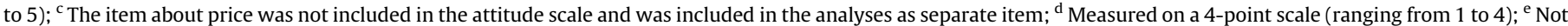
measured for fat intake; ${ }^{\mathrm{f}}$ Scores were reversed for high-energy snack and high-fat products. $\alpha=$ Cronbach's alpha.

were assessed in the baseline questionnaire. To assess educational level, participants had to indicate their highest attained educational level (Verweij, 2008). Educational level was first divided into three groups; high (higher vocational education and university), moderate (intermediate vocational education and higher secondary or pre-university education), and low (no education through lower general secondary education). Because differences in intake levels between low- and moderate-educated individuals are reported to be small (van Rossum et al., 2011), educational level was subsequently dichotomized into two groups: 0 for high educated and 1 for low and moderate educated. Ethnicity (non-Western (0) vs. Western (1)) was defined according to the criteria of Statistics Netherlands (Keij, 2000); a participant was considered to be of Western ethnicity if both parents were born in Europe (except for Turkey), North America, Oceania, Indonesia, or Japan. If at least one parent was born elsewhere, the participant was considered to be of non-Western ethnicity.

\subsection{Statistical analyses}

All analyses were conducted for each dietary outcome separately. In all analyses, the basic and plus intervention group were dummy coded with the control condition as reference group. Descriptive statistics were used to describe the groups at baseline, for each outcome measure separately. Multiple logistic regression analyses were conducted to test for selective dropout or incomplete data for a dietary outcome. Demographics (i.e. gender, age, ethnicity, education, place of residence), intervention group, and baseline intake of fruit, high-energy snacks, or fat were regressed on dropout (yes $=1 /$ no $=0$ ) at the first and second follow-up measurement. To study equality of the intervention groups at baseline, two multiple logistic regression analyses per dietary outcome were conducted with intervention (basic vs. control or plus vs. control) as dependent variable and age, gender, ethnicity, education, place of residence, and baseline intake of fruit, highenergy snacks or fat as independent variables.

For the mediation analyses, the model depicted in Fig. 3 was used. Path $\mathrm{c}$ in this model refers to the total association between the intervention and the intake of fruit, high-energy snacks, or fat; path a refers to the associations between the intervention and potential mediating variables; path $\mathrm{b}$ refers to the associations between potential mediating variables and the intake of fruit, high-energy snacks, or fat, adjusted for intervention. First, the total association of the intervention with the dietary outcomes (path c) was examined by a multiple linear regression analysis, adjusted for background characteristics, baseline value of potential mediating variables, and baseline value of intake. For the significant associations between intervention and dietary outcome, mediation was determined with the joint-significance test (MacKinnon, Lockwood, Hoffman, West, \& Sheets, 2002). This test states that a variable is a mediating variable when both path a and path $b$ are significant. The associations between the intervention and 


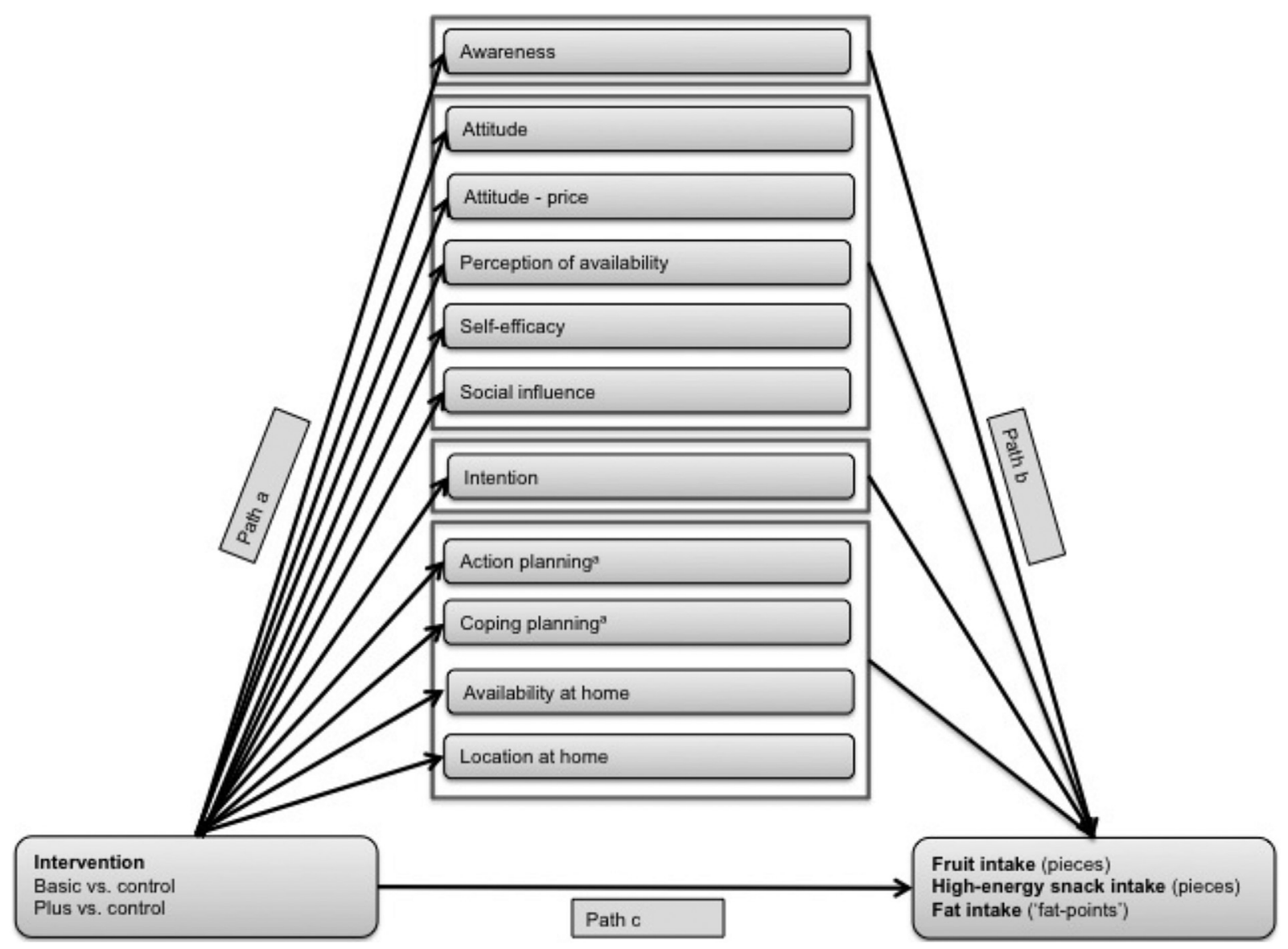

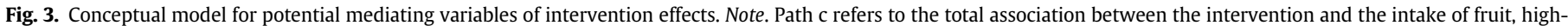

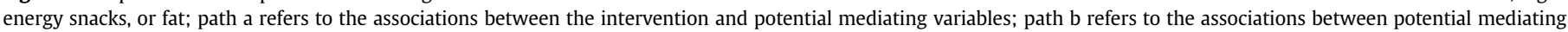

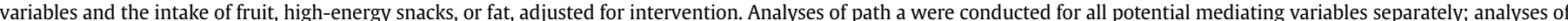

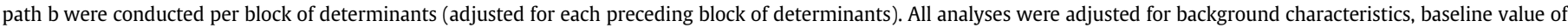
potential mediating variables, and baseline value of intake. ${ }^{\text {a }}$ Not measured for fat intake.

potential mediating variables (path a) were assessed with multiple linear- and logistic regression analyses, each time correcting for the background characteristics (i.e. place of residence, age, gender, education), baseline value of potential mediating variables, and baseline value of intake. For each dietary outcome, the associations between the potential mediating variables and the dietary outcome (path b) were assessed using linear regression analyses. These analyses were adjusted for background characteristics, baseline value of potential mediating variables, intervention, and each preceding (block of) determinants (see Fig. 3). Thus path b was assessed with one of four multiple linear regression analyses; for awareness the regression included background characteristics, baseline value of potential mediating variables, baseline value of intake, intervention dummy's, and awareness as independent variables; for attitude, perception of price, perception of availability, self-efficacy, and social influence these variables were added to the previously described regression analysis; for intention the regression additionally included intention as independent variable; for action planning, coping planning, and the availability and location of food products at home, these variables were added to the previously described regression analysis.

Educational differences in mediating variables were examined by adding interaction terms to the analyses (i.e. 'intervention dummy*education' for path c and a and 'potential mediating variable*education' for path b). When an interaction term was significant $(p \leq .10)$ in both path a and $\mathrm{b}$, or in path a or $\mathrm{b}$ with a significant main association in the other path, the analyses of the particular path were stratified to educational level. For readability, parameters of the stratified analyses are not reported in the tables, but are reported in the text when stratified analyses showed a significant mediating variable.

The analyses were conducted for the associations of T1 mediating variables with $\mathrm{T} 2$ dietary outcomes, for T1 mediating variables with $\mathrm{T} 1$ dietary outcomes, and for T2 mediating variables with T2 dietary outcomes. Analyses were conducted at all time points, because mediation can take place at different time points. In addition, some variables may play a role in the first phase of behavior change (e.g. awareness) and others in a later phase (such as action- and coping planning). Exploring mediating variables at both $\mathrm{T} 1$ and $\mathrm{T} 2$, therefore, is most informative.

The results of the separate regression analyses were verified by bootstrapping (Field, 2009). All regression analyses were adjusted for place of residence and variables that were predictors for dropout or differed between study groups. All tests were 2-sided and alpha levels were set at .05 for single variables and at .10 for interaction terms. All analyses were performed with SPSS version 22.0 (IBM Corp, Armonk, NY, USA).

\section{Results}

\subsection{Loss to follow-up}

A total of 1349 participants filled out the baseline questionnaire. At baseline, 803 participants did not comply with guidelines for 
fruit intake, of which 275 dropped out between T0 and T1 and 117 between T1 and T2 (total dropout $48.8 \%$; total sample $=411$ ). At baseline, 808 participants had an intake of $>2$ high-energy snacks, of which 258 dropped out between T0 and T1 and 121 between T1 and T2 (total dropout 46.9\%; total sample $=429$ ). A total of 627 participants did not comply with the guidelines for saturated fat, of which 204 dropped out between T0 and T1 and 91 between T1 and T2 (total dropout 47.1\%; total sample $=332$ ). Predictors for dropout differed between the three samples, but included age, gender, education, place of residence, and intervention group (Table S1 (additional file)). These predictors were included as covariates in all regression analyses.

\subsection{Participant characteristics}

The distribution of age, gender, education, ethnicity, and place of residence per study sample are shown in Table 2 . Differences between the intervention- and control groups were found for age, gender, and education, but the patterns differed per study sample. The scores on potential mediating variables at all time points are shown in Table S2 (additional file).

\subsection{Mediation analyses}

\subsubsection{Fruit intake}

The plus version was associated with a higher fruit intake compared to the control program (path c) at $\mathrm{T} 1(\beta=0.13,95 \% \mathrm{Cl}$ $(0.03,0.23), p=.01)$ and $\mathrm{T} 2(\beta=0.19,95 \% \mathrm{CI}(0.09,0.29), p<.001)$, but the basic version was not $\left(\beta_{\mathrm{T} 1}=0.03,95 \% \mathrm{CI}(-0.08,0.13)\right.$, $\left.p=.62 / \beta_{\mathrm{T} 2}=0.07,95 \% \mathrm{CI}(-0.03,0.17), p=.19\right)$. Therefore, only mediating variables for the plus version were explored.

No mediating variables were identified in the analyses of T1 mediating variables - T2 fruit intake and T1 mediating variables T1 fruit intake (Table 3). In the analyses of T2 mediating variables T2 fruit intake, intention to consume 2 pieces of fruit $\left(\beta_{\text {path a }}=0.14\right.$, $95 \% \mathrm{CI}(0.05,0.23), p=.003 / \beta_{\text {path } \mathrm{b}}=0.23,95 \% \mathrm{CI}(0.10,0.36)$, $p=.001)$ and the availability of fruit at home $\left(\beta_{\text {path a }}=0.13,95 \% \mathrm{CI}\right.$ $\left.(0.05,0.21), p=.003 / \beta_{\text {path } \mathrm{b}}=0.17,95 \% \mathrm{CI}(0.05,0.29), p=.01\right)$ were identified as mediating variables. For high-educated participants, attitude was also a mediating variable $\left(\beta_{\text {path a }}=0.19,95 \% \mathrm{CI}(0.05\right.$, $\left.0.33), p=.01 / \beta_{\text {path } \mathrm{b}}=0.20,95 \% \mathrm{CI}(0.04,0.35), p=.01\right)$.

\subsubsection{High-energy snack intake}

The basic version was associated with a lower high-energy

Table 2

Baseline characteristics and results of multiple logistic regression analyses.

\begin{tabular}{|c|c|c|c|c|c|c|}
\hline & \multirow[t]{2}{*}{ Total } & \multirow[t]{2}{*}{ Control } & \multirow[t]{2}{*}{ Basic } & \multirow[t]{2}{*}{ Plus } & \multicolumn{2}{|l|}{ OR $(95 \% \mathrm{CI})^{\mathrm{a}}$} \\
\hline & & & & & Basic vs. control & Plus vs. control \\
\hline \multicolumn{7}{|l|}{ Sample fruit ${ }^{\mathrm{b}}$} \\
\hline$N$ & 411 & 150 & 135 & 126 & & \\
\hline Age (years), mean $(S D)$ & $50.04(10.07)$ & $51.06(9.66)$ & $50.39(10.07)$ & $48.46(10.44)$ & $1.00(0.97,1.02)$ & $0.97(0.95,0.999)^{*}$ \\
\hline \multicolumn{7}{|l|}{ Gender, $n(\%)$} \\
\hline Male & $161(39.2)$ & $58(38.7)$ & $49(36.3)$ & $54(42.9)$ & 1 & 1 \\
\hline Female & $250(60.8)$ & $92(61.3)$ & $86(63.7)$ & $72(57.1)$ & $1.03(0.63,1.70)$ & $0.79(0.48,1.29)$ \\
\hline \multicolumn{7}{|l|}{ Ethnicity $(n=410), n(\%)$} \\
\hline Western & $408(99.3)$ & $149(99.3)$ & $134(99.3)$ & $125(99.2)$ & - & - \\
\hline Non-western & $2(0.5)$ & $0(0)$ & $1(0.7)$ & $1(0.8)$ & $-^{\mathrm{e}}$ & $-^{\mathrm{e}}$ \\
\hline \multicolumn{7}{|l|}{ Education, $n(\%)$} \\
\hline High & $186(45.3)$ & $59(39.3)$ & $72(53.3)$ & $55(43.7)$ & & \\
\hline Low/moderate & $225(54.7)$ & $91(60.7)$ & $63(46.7)$ & $71(56.3)$ & $0.62(0.38,1.01)$ & $0.93(0.56,1.55)$ \\
\hline Fruit intake, Mean (SD) & $1.07(0.53)$ & $1.07(0.52)$ & $1.13(0.55)$ & $1.01(0.52)$ & $1.23(0.78,1.94)$ & $0.77(0.48,1.24)$ \\
\hline \multicolumn{7}{|l|}{ Sample snacks ${ }^{\mathrm{c}}$} \\
\hline $\mathrm{N}$ & 429 & 150 & 145 & 134 & & \\
\hline Age (years), mean $(S D)$ & $50.25(10.12)$ & $51.57(9.56)$ & $49.73(10.40)$ & $49.35(10.33)$ & $0.98(0.96,1.01)$ & $0.97(0.95,0.999)^{*}$ \\
\hline \multicolumn{7}{|l|}{ Gender, $n(\%)$} \\
\hline Male & $158(36.8)$ & $53(35.3)$ & $53(36.6)$ & $52(38.8)$ & 1 & 1 \\
\hline Female & $271(63.2)$ & $97(64.7)$ & $92(63.4)$ & $82(61.2)$ & $0.93(0.57,1.52)$ & $0.80(0.49,1.33)$ \\
\hline \multicolumn{7}{|l|}{ Ethnicity $(n=721), n(\%)$} \\
\hline Western & $423(98.6)$ & $147(98.0)$ & $143(98.6)$ & $133(99.3)$ & 1 & 1 \\
\hline Non-western & $6(1.4)$ & $3(2.0)$ & $2(1.4)$ & $1(0.7)$ & $2.04(0.31,13.52)$ & $4.05(0.38,42.80)$ \\
\hline \multicolumn{7}{|l|}{ Education, $n(\%)$} \\
\hline High & $199(46.4)$ & $57(38.0)$ & $78(53.8)$ & $64(47.8)$ & 1 & 1 \\
\hline Low/moderate & $230(53.6)$ & $93(62.0)$ & $67(46.2)$ & $70(52.2)$ & $0.56(0.34,0.90)^{*}$ & $0.70(0.43,1.14)$ \\
\hline Snacks intake, Mean (SD) & $4.67(2.72)$ & $4.62(2.56)$ & $4.72(2.92)$ & $4.67(2.68)$ & $1.02(0.94,1.11)$ & $1.00(0.91,1.10)$ \\
\hline \multicolumn{7}{|l|}{ Sample fat $^{d}$} \\
\hline $\mathrm{N}$ & 332 & 114 & 115 & 103 & & \\
\hline Age (years), mean $(S D)$ & $51.75(9.26)$ & $53.54(8.24)$ & $51.38(9.64)$ & $50.19(9.66)$ & $0.97(0.94,1.01)$ & $0.95(0.92,0.98)^{*}$ \\
\hline \multicolumn{7}{|l|}{ Gender, $n(\%)$} \\
\hline Male & $126(38.0)$ & $39(34.2)$ & $40(34.8)$ & $47(45.6)$ & 1 & 1 \\
\hline Female & $206(62.0)$ & $75(65.8)$ & $75(65.2)$ & $56(54.4)$ & $0.77(0.43,1.39)$ & $0.41(0.22,0.77)^{*}$ \\
\hline \multicolumn{7}{|l|}{ Ethnicity $(n=331), n(\%)$} \\
\hline Western & $329(99.1)$ & $113(99.1)$ & $114(99.1)$ & $102(99.0)$ & - & - \\
\hline Non-western & $2(0.6)$ & $0(0.0)$ & $1(0.9)$ & $1(1.0)$ & $-^{\mathrm{e}}$ & $-^{\mathrm{e}}$ \\
\hline \multicolumn{7}{|l|}{ Education, $n(\%)$} \\
\hline High & $144(43.4)$ & $41(36.0)$ & $59(51.3)$ & $44(42.7)$ & 1 & 1 \\
\hline Low/moderate & $188(56.6)$ & $73(64.0)$ & $56(48.7)$ & $59(57.3)$ & $0.62(0.35,1.08)$ & $0.99(0.55,1.78)$ \\
\hline Fat intake, Mean (SD) & $22.65(4.11)$ & $23.25(4.47)$ & $22.30(4.18)$ & $22.38(3.54)$ & $0.94(0.88,1.01)$ & $0.90(0.83,0.98)^{*}$ \\
\hline
\end{tabular}

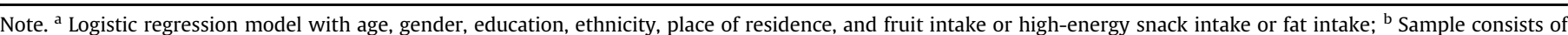

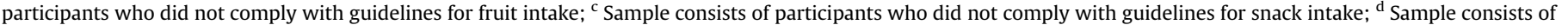
participants who did not comply with guidelines for fat intake; ${ }^{\text {e }}$ No OR could be derived, because sub-groups were too small.

* Significant at $p \leq .05$. 
Table 3

Results of joint-significance test (path a and path b) for fruit intake $(n=411)$.

\begin{tabular}{|c|c|c|c|c|c|c|}
\hline \multirow{4}{*}{ Mediating variable } & \multicolumn{2}{|l|}{$\mathrm{T} 1-\mathrm{T} 2$} & \multicolumn{2}{|l|}{$\mathrm{T} 1-\mathrm{T} 1$} & \multicolumn{2}{|l|}{$\mathrm{T} 2-\mathrm{T} 2$} \\
\hline & Path a (T1) & Path b (T2) & Path a & Path b & Path a & Path b \\
\hline & \multicolumn{2}{|l|}{ Plus vs. control } & \multicolumn{2}{|l|}{ Plus vs. control ${ }^{\#}$} & \multicolumn{2}{|l|}{ Plus vs. control } \\
\hline & $\beta / O R(95 \% \mathrm{CI})$ & $\beta(95 \% \mathrm{CI})$ & $\beta / O R(95 \% \mathrm{CI})$ & $\beta(95 \% \mathrm{CI})$ & $\beta / O R(95 \% \mathrm{CI})$ & $\beta(95 \% \mathrm{CI})$ \\
\hline Awareness & $O R=0.96(0.57,1.64)$ & $\beta=0.09(-0.01,0.18)^{b}$ & $O R=0.96(0.57,1.64)$ & $\beta=0.29(0.20,0.38)^{b, *}$ & $O R=1.11(0.65,1.89)$ & $\beta=0.26(0.18,0.35)^{\mathrm{b}, *}$ \\
\hline Attitude & $\beta=0.04(-0.04,0.13)$ & $\beta=0.31(0.18,0.43)^{c, *}$ & $\beta=0.04(-0.04,0.13)$ & $\beta=0.11(-0.01,0.23)^{c}$ & $\begin{array}{l}\beta=0.09(-0.003 \\
0.18)^{\$}\end{array}$ & $\begin{array}{l}\beta=0.10(-0.01 \\
0.22)^{c, \$}\end{array}$ \\
\hline Attitude - price & $\beta=0.04(-0.06,0.14)$ & $\beta=-0.01(-0.11,0.09)^{c}$ & $\beta=0.04(-0.06,0.14)$ & $\begin{array}{l}\beta=-0.04(-0.14 \\
0.05)^{\mathrm{c}}\end{array}$ & $\beta=0.01(-0.09,0.11)$ & $\beta=0.01(-0.08,0.11)^{c}$ \\
\hline $\begin{array}{l}\text { Perception } \\
\text { availability }\end{array}$ & $\begin{array}{l}\beta=-0.001(-0.10 \\
0.10)\end{array}$ & $\beta=-0.05(-0.15,0.05)^{c}$ & $\begin{array}{l}\beta=-0.001(-0.10 \\
0.10)\end{array}$ & $\begin{array}{l}\beta=-0.003(-0.10 \\
0.09)^{c}\end{array}$ & $\begin{array}{l}\beta=-0.02(-0.12, \\
0.08)\end{array}$ & $\beta=0.01(-0.08,0.11)^{c}$ \\
\hline Self-efficacy & $\begin{array}{l}\beta=-0.04(-0.13 \\
0.05)\end{array}$ & $\beta=0.23(0.12,0.35)^{c, *}$ & $\begin{array}{l}\beta=-0.04(-0.13 \\
0.05)\end{array}$ & $\boldsymbol{\beta}=0.38(0.27,0.49)^{c, *}$ & $\beta=0.08(-0.01,0.17)$ & $\beta=0.37(0.26,0.48)^{c . *}$ \\
\hline Social influence & $\beta=0.02(-0.07,0.12)$ & $\beta=-0.11(-0.21,-0.001)^{\mathrm{c}, *}$ & $\beta=0.02(-0.07,0.12)$ & $\beta=0.03(-0.07,0.13)^{c}$ & $\beta=0.05(-0.05,0.15)$ & $\beta=0.00(-0.10,0.10)^{c}$ \\
\hline Intention & $\beta=0.05(-0.04,0.15)$ & $\beta=0.08(-0.06,0.22)^{\mathrm{d}}$ & $\beta=0.05(-0.04,0.15)$ & $\begin{array}{l}\beta=0.11(-0.02 \\
0.24)^{\mathrm{d}, \$}\end{array}$ & $\beta=0.14(0.05,0.23)^{*}$ & $\beta=0.23(0.10,0.36)^{d, *}$ \\
\hline Action planning & $\beta=0.05(-0.05,0.15)$ & $\beta=0.01(-0.13,0.14)^{\mathrm{e}}$ & $\beta=0.05(-0.05,0.15)$ & $\begin{array}{l}\beta=-0.004(-0.13 \\
0.12)^{\mathrm{e}}\end{array}$ & $\beta=0.14(0.03,0.24)^{*}$ & $\begin{array}{l}\beta=-0.003(-0.14 \\
0.13)^{\mathrm{e}}\end{array}$ \\
\hline Coping planning & $\beta=0.05(-0.05,0.15)$ & $\beta=-0.01(-0.15,0.12)^{e}$ & $\beta=0.05(-0.05,0.15)$ & $\beta=0.07(-0.05,0.20)^{\mathrm{e}}$ & $\beta=0.12(0.02,0.22)^{*}$ & $\begin{array}{l}\beta=-0.03(-0.17 \\
0.10)^{\mathrm{e}}\end{array}$ \\
\hline Availability at home & $\beta=0.07(-0.01,0.15)$ & $\beta=0.20(0.08,0.32)^{\mathrm{e}, *}$ & $\beta=0.07(-0.01,0.15)$ & $\beta=0.21(0.09,0.32)^{\mathrm{e}, *}$ & $\beta=0.13(0.05,0.21)^{*}$ & $\beta=0.17(0.05,0.29)^{e, *}$ \\
\hline Location at home & $O R=1.07(0.48,2.37)$ & $\beta=0.04(-0.06,0.13)^{\mathrm{e}}$ & $O R=1.07(0.48,2.37)$ & $\beta=0.04(-0.05,0.13)^{\mathrm{e}}$ & $O R=0.99(0.41,2.38)$ & $\beta=0.01(-0.08,0.11)^{\mathrm{e}}$ \\
\hline
\end{tabular}

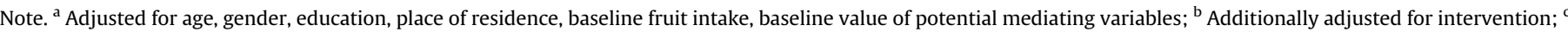

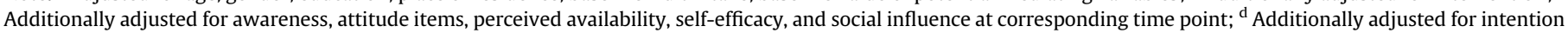
at corresponding time point; ${ }^{\text {e }}$ Additionally adjusted for action planning, coping planning, availability at home, and location at home at corresponding time point.

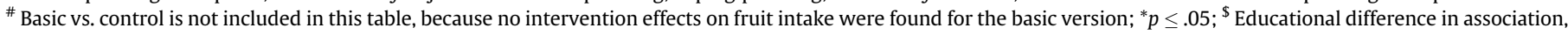
reported coefficient represents main association (not stratified).

Bold $=$ significant association at $\alpha=.05$; Bold and italic $=$ significant mediating variable at $\alpha=.05$ (significant association in both path a and path $b$ ).

snack intake compared to the control program (path c) at T1 $(\beta=-0.14,95 \% \mathrm{CI}(-0.23,-0.04), p=.004)$. At $\mathrm{T} 2$, this association was not significant $(\beta=-0.09,95 \% \mathrm{CI}(-0.18,0.01), p=.06)$ and was, therefore, not taken into account in the mediation analyses. The plus version was associated with a lower high-energy snack intake compared to the control program at T1 ( $\beta=-0.16,95 \% \mathrm{CI}$ $(-0.25,-0.06), p=.001)$. At T2, education was found to moderate the effects of the plus version $(p=.02)$ and the plus version was associated with a lower high-energy snack intake among higheducated participants only $(\beta=-0.26,95 \%$ CI $(-0.40,-0.11)$, $p<.001$ ). Therefore, for the plus version at T2, only the mediating variables among high-educated participants were explored.

No mediating variables were identified in the analyses of T1 mediating variables - T2 snack intake and $\mathrm{T} 2$ mediating variables T2 snack intake (Table 4). In the analyses of T1 mediating variables - T1 snack intake, educational differences were found in the association of the basic version with availability of snacks at home; the basic version was associated with having snacks at home less often among low/moderate-educated participants only ( $\beta=0.15$, $95 \% \mathrm{CI}(0.02,0.28), p=.02)$. Having high-energy snacks at home less often was also associated with a lower high-energy snack intake $(\beta=-0.22,95 \% \mathrm{CI}(-0.31,-0.12), p<.001)$ and was therefore identified as a mediating variable among low/moderateeducated participants.

\subsubsection{Fat intake}

The basic version was associated with a lower saturated fat intake compared to the control program (path c) at T1 $(\beta=-0.17$, $95 \% \mathrm{CI}(-0.28,-0.06), p=.002)$ and $\mathrm{T} 2(\beta=-0.14,95 \% \mathrm{CI}$ $(-0.25,-0.03), p=.01)$, but no effects were found for the plus version $\left(\beta_{\mathrm{T} 1}=-0.07,95 \% \mathrm{CI}(-0.17,0.04), p=.22 / \beta_{\mathrm{T} 2}=-0.10,95 \%\right.$ $\mathrm{CI}(-0.21,0.01), p=.07)$. Therefore, only mediating variables of the basic version were explored.

In the analyses of T1 mediating variables - T2 fat intake and T2 mediating variables - T2 fat intake no mediating variables were found (Table 5). In the analyses of T1 mediating variables - T1 fat intake, educational differences were found in the association of the basic version with subjective norm; the basic version was positively associated with subjective norm among high-educated participants only ( $\beta=0.19,95 \% \mathrm{CI}(0.02,0.35), p=.03)$. In addition, subjective norm was positively associated with fat intake $(\beta=0.10,95 \% \mathrm{CI}$ $(0.01,0.20), p=.04)$ and was therefore identified as a mediating variable among high-educated participants, although this was in an unexpected direction.

\section{Discussion}

No consistent pattern of mediating variables was found. There were some indications that attitude, subjective norm, intention, and availability at home mediated some of the intervention effects; however, the mediating variables differed per time point, per intervention version, and per dietary behavior. Some educational differences were found in the mediating variables: subjective norm mediated the effect of the basic version on saturated fat intake and attitude mediated the effect of the plus version on fruit intake among high-educated participants, whereas the availability of high-energy snacks at home mediated the effect of the basic version on snack intake among lower/moderate-educated participants.

Three cognitive variables were identified as mediating variables. Attitude and subjective norm mediated intervention effects among high-educated participants only. This educational difference could be explained by the highly text-based feedback that was provided in the intervention, which may be better processed by higheducated people (Cutler \& Lleras-Muney, 2010). The association between subjective norm and saturated fat intake was in an unexpected direction, but may reflect reversed causality since we measured subjective norm regarding consuming less fat (i.e. participants who reported a high saturated fat intake may think that important others think that the participant should decrease his/her 
Table 4

Results of joint-significance test (path a and path $\mathrm{b})$ for high-energy snack intake $(n=429)^{\mathrm{a}}$.

\begin{tabular}{|c|c|c|c|c|c|c|c|}
\hline \multirow{4}{*}{ Mediating variable } & \multicolumn{2}{|l|}{$\mathrm{T} 1-\mathrm{T} 2$} & \multicolumn{3}{|l|}{$\mathrm{T} 1-\mathrm{T} 1$} & \multicolumn{2}{|l|}{$\mathrm{T} 2-\mathrm{T} 2$} \\
\hline & Path a (T1) & Path b (T2) & \multirow{2}{*}{$\begin{array}{l}\text { Path a } \\
\text { Basic vs. control }\end{array}$} & \multirow[b]{2}{*}{ Plus vs. control } & \multirow[t]{2}{*}{ Path b } & \multirow{2}{*}{$-\frac{\text { Path a }}{\text { Plus vs. control }}$} & \multirow[t]{2}{*}{ Path $b^{\#}$} \\
\hline & \multicolumn{2}{|l|}{ Plus vs. control ${ }^{\#, ~ \& ~}$} & & & & & \\
\hline & $\beta / O R(95 \% \mathrm{CI})$ & $\beta(95 \% \mathrm{CI})$ & $\beta / O R(95 \% \mathrm{CI})$ & $\beta / O R(95 \% \mathrm{CI})$ & $\beta(95 \% \mathrm{CI})$ & $\beta / O R(95 \% \mathrm{Cl})$ & $\beta(95 \% \mathrm{CI})$ \\
\hline Awareness & $O R=0.56(0.24,1.34)$ & $\beta=0.01(-0.11,0.13)^{b}$ & $\begin{array}{l}O R=1.87(1.09, \\
3.21)^{*}\end{array}$ & $O R=1.15(0.66,2.01)^{\S}$ & $\beta=-0.03(-0.12,0.05)^{\mathrm{b}}$ & $O R=1.19(0.52,2.69)$ & $\beta=-0.05(-0.17,0.07)^{b}$ \\
\hline Attitude & $\begin{array}{l}\beta=-0.01(-0.18 \\
0.15)\end{array}$ & $\beta=0.02(-0.11,0.15)^{\mathrm{c}}$ & $\begin{array}{l}\beta=0.01(-0.10 \\
0.12)\end{array}$ & $\beta=0.02(-0.09,0.12)$ & $\beta=0.01(-0.08,0.10)^{c}$ & $\beta=-0.02(-0.18,0.14)$ & $\beta=0.01(-0.13,0.15)^{c}$ \\
\hline Attitude - price & $\beta=0.07(-0.10,0.23)$ & $\beta=-0.06(-0.18,0.07)^{c}$ & $\begin{array}{l}\beta=0.004(-0.10 \\
0.11)\end{array}$ & $\beta=0.01(-0.09,0.12)$ & $\beta=-0.01(-0.09,0.08)^{c}$ & $\beta=-0.03(-0.19,0.12)$ & $\beta=0.06(-0.07,0.19)^{c}$ \\
\hline Attitude - taste & $\begin{array}{l}\beta=-0.003(-0.16 \\
0.16)\end{array}$ & $\beta=-0.17(-0.29,-0.04)^{c, *}$ & $\begin{array}{l}\beta=-0.02(-0.12 \\
0.09)\end{array}$ & $\beta=0.001(-0.10,0.11)$ & $\beta=-0.05(-0.13,0.04)^{c}$ & $\beta=0.07(-0.10,0.23)$ & $\beta=-0.05(-0.17,0.08)^{c}$ \\
\hline Perception availability & $\beta=0.24(0.08,0.40)^{*}$ & $\beta=-0.03(-0.15,0.09)^{c}$ & $\begin{array}{l}\beta=0.07(-0.03 \\
0.18)\end{array}$ & $\beta=0.07(-0.04,0.18)^{\S}$ & $\beta=-0.01(-0.10,0.07)^{c}$ & $\beta=0.08(-0.08,0.24)$ & $\beta=-0.21(-0.32,-0.09)^{c, *}$ \\
\hline Self-efficacy - difficulty & $\beta=0.03(-0.12,0.17)$ & $\beta=-0.08(-0.22,0.06)^{c}$ & $\begin{array}{l}\beta=-0.03(-0.12, \\
0.07)\end{array}$ & $\beta=-0.02(-0.12,0.08)$ & $\beta=-0.20(-0.30,-0.09)^{c, *}$ & $\beta=-0.04(-0.19,0.11)$ & $\beta=-0.06(-0.20,0.08)^{c}$ \\
\hline Self-efficacy - succeeding & $\begin{array}{l}\beta=-0.07(-0.23 \\
0.09)\end{array}$ & $\beta=-0.07(-0.21,0.06)^{c}$ & $\begin{array}{l}\beta=-0.05(-0.15 \\
0.06)\end{array}$ & $\beta=-0.08(-0.19,0.03)$ & $\beta=-0.03(-0.13,0.06)^{c}$ & $\beta=0.08(-0.09,0.24)$ & $\beta=-0.14(-0.28,-0.01)^{c, *}$ \\
\hline Social influence - modeling & $\beta=0.14(-0.01,0.30)$ & $\beta=-0.11(-0.25,0.03)^{c}$ & $\begin{array}{l}\beta=0.05(-0.05 \\
0.15)^{\$}\end{array}$ & $\beta=0.01(-0.09,0.11)^{\$}$ & $\beta=-0.03(-0.12,0.06)^{c}$ & $\beta=-0.02(-0.19,0.14)$ & $\beta=0.01(-0.11,0.14)^{c}$ \\
\hline $\begin{array}{l}\text { Social influence - subjective } \\
\text { norm }\end{array}$ & $\begin{array}{l}\beta=-0.03(-0.18 \\
0.11)\end{array}$ & $\beta=0.15(0.01,0.29)^{c, *}$ & $\begin{array}{l}\beta=-0.01(-0.11 \\
0.08)\end{array}$ & $\beta=-0.07(-0.16,0.03)$ & $\beta=0.10(0.01,0.20)^{c, *}$ & $\beta=-0.01(-0.16,0.14)$ & $\beta=0.17(0.03,0.31)^{c, *}$ \\
\hline Intention & $\begin{array}{l}\beta=-0.15(-0.30 \\
0.01)\end{array}$ & $\beta=-0.14(-0.27,-0.003)^{\mathrm{d}, *}$ & $\begin{array}{l}\beta=0.02(-0.08 \\
0.12)\end{array}$ & $\begin{array}{l}\beta \\
*\end{array}=-0.12(-0.22,-0.02)$ & $\beta=0.01(-0.09,0.10)^{\mathrm{d}, \$}$ & $\begin{array}{l}\beta \\
*\end{array}=-0.16(-0.31,-0.01)$ & $\beta=0.03(-0.11,0.17)^{d}$ \\
\hline Action planning & $\begin{array}{l}\beta=-0.01(-0.17 \\
0.15)\end{array}$ & $\beta=0.04(-0.16,0.24)^{\mathrm{e}}$ & $\begin{array}{l}\beta=0.03(-0.07 \\
0.14)\end{array}$ & $\beta=-0.02(-0.13,0.08)$ & $\beta=-0.03(-0.16,0.10)^{\mathrm{e}}$ & $\beta=0.11(-0.04,0.27)$ & $\beta=-0.05(-0.26,0.17)^{\mathrm{e}}$ \\
\hline Coping planning & $\beta=0.05(-0.11,0.20)$ & $\beta=-0.07(-0.27,0.13)^{\mathrm{e}}$ & $\begin{array}{l}\beta=0.10(0.001 \\
0.21)^{*}\end{array}$ & $\beta=0.05(-0.05,0.16)$ & $\beta=-0.04(-0.17,0.10)^{\mathrm{e}}$ & $\beta=0.14(-0.02,0.29)$ & $\beta=-0.05(-0.26,0.16)^{\mathrm{e}}$ \\
\hline Availability at home & $\begin{array}{l}\beta=-0.13(-0.28 \\
0.01)\end{array}$ & $\beta=-0.22(-0.35,-0.08)^{\mathrm{e}, *}$ & $\begin{array}{l}\beta=0.04(-0.06 \\
0.13)^{\$}\end{array}$ & $\beta=-0.04(-0.14,0.06)$ & $\beta=-0.22(-0.31,-0.12)^{\mathrm{e}, *}$ & $\beta=-0.01(-0.16,0.14)$ & $\beta=-0.33(-0.48,-0.19)^{\mathrm{e}, *}$ \\
\hline Location at home & $O R=2.03(0.45,9.26)$ & $\beta=-0.04(-0.17,0.08)^{e}$ & $\begin{array}{l}O R=1.34(0.57 \\
3.18)\end{array}$ & $O R=0.95(0.41,2.23)$ & $\beta=-0.08(-0.16,0.002)^{e, \$}$ & $O R=1.06(0.26,4.31)$ & $\beta=0.04(-0.08,0.16)^{e}$ \\
\hline
\end{tabular}

Note. ${ }^{\mathrm{a}}$ Adjusted for age, gender, education, place of residence, baseline snack intake, baseline value of potential mediating variables; ${ }^{\mathrm{b}}$ Additionally adjusted for intervention; ${ }^{\mathrm{c}}$ Additionally adjusted for awareness, attitude items,

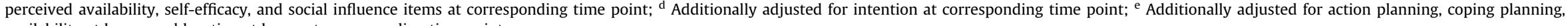

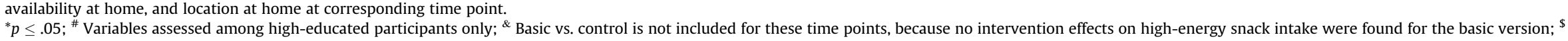
Educational difference in association, reported coefficient represents main association (not stratified).

Bold $=$ significant association at $\alpha=.05$. 
Table 5

Results of joint-significance test (path a and path b) for fat intake $(n=332)^{\mathrm{a}}$.

\begin{tabular}{|c|c|c|c|c|c|c|}
\hline & $\mathrm{T} 1-\mathrm{T} 2$ & & $\mathrm{~T} 1-\mathrm{T} 1$ & & $\mathrm{~T} 2-\mathrm{T} 2$ & \\
\hline & Path a (T1) & Path b (T2) & Path a & Path b & Path a & Path b \\
\hline \multirow[t]{2}{*}{ Mediating variables } & $\begin{array}{l}\text { Basic vs. } \\
\text { control }^{\#}\end{array}$ & & $\begin{array}{l}\text { Basic vs. } \\
\text { control }^{\#}\end{array}$ & & $\begin{array}{l}\text { Basic vs. } \\
\text { control }^{\#}\end{array}$ & \\
\hline & $\beta / O R(95 \% \mathrm{CI})$ & $\beta(95 \% \mathrm{CI})$ & $\beta / O R(95 \% \mathrm{CI})$ & $\beta(95 \% \mathrm{CI})$ & $\beta / O R(95 \% \mathrm{CI})$ & $\beta(95 \% \mathrm{CI})$ \\
\hline Awareness & \multicolumn{2}{|c|}{$\begin{array}{l}O R=1.23\left(0.68, \boldsymbol{\beta}=-\mathbf{0 . 2 0}(-\mathbf{0 . 2 9},-\mathbf{0 . 1 1})^{\mathrm{b}, *}\right. \\
2.23)\end{array}$} & \multicolumn{2}{|c|}{$\begin{array}{l}O R=1.23\left(0.68, \boldsymbol{\beta}=-0.47(-0.55,-0.39)^{\mathrm{b}, *}\right. \\
2.23)\end{array}$} & $\begin{array}{l}O R=1.35(0.75 \\
2.44)\end{array}$ & $\beta=-0.49(-0.57,-0.41)^{\mathrm{b}, *}$ \\
\hline Attitude & $\begin{array}{l}\beta=-0.01 \\
(-0.13,0.10)\end{array}$ & $\beta=-0.08(-0.19,0.03)^{c}$ & $\begin{array}{l}\beta=-0.01 \\
(-0.13,0.10)\end{array}$ & $\beta=0.04(-0.06,0.13)^{\mathrm{c}}$ & $\begin{array}{l}\beta=-0.04 \\
(-0.15,0.06)\end{array}$ & $\beta=0.07(-0.02,0.17)^{c}$ \\
\hline Attitude - price & $\begin{array}{l}\beta=0.02(-0.11 \\
0.14)\end{array}$ & $\beta=-0.11(-0.21,-0.01)^{c, *}$ & $\begin{array}{l}\beta=0.02(-0.11 \\
0.14)\end{array}$ & $\beta=-0.04(-0.12,0.04)^{\mathrm{c}}$ & $\begin{array}{l}\beta=0.03(-0.09 \\
0.16)\end{array}$ & $\beta=-0.02(-0.10,0.06)^{c}$ \\
\hline Attitude - taste & $\begin{array}{l}\beta=-0.06 \\
(-0.18,0.06)\end{array}$ & $\beta=-0.07(-0.18,0.03)^{c}$ & $\begin{array}{l}\beta=-0.06 \\
(-0.18,0.06)\end{array}$ & $\beta=-0.09(-0.18,-0.003)^{c, *}$ & $\begin{array}{l}\beta=0.08(-0.03 \\
0.20)\end{array}$ & $\beta=-0.07(-0.16,0.02)^{c, \$}$ \\
\hline Perception availability & $\begin{array}{l}\beta=-0.10 \\
(-0.22,0.02)\end{array}$ & $\beta=0.01(-0.09,0.11)^{\mathrm{c}, \$}$ & $\begin{array}{l}\beta=-0.10 \\
(-0.22,0.02)\end{array}$ & $\beta=0.05(-0.03,0.14)^{c, \$}$ & $\begin{array}{l}\beta=-0.08 \\
(-0.20,0.04)\end{array}$ & $\beta=0.08(-0.01,0.16)^{c}$ \\
\hline $\begin{array}{l}\text { Self-efficacy - } \\
\quad \text { difficulty }\end{array}$ & $\begin{array}{l}\beta=-0.03 \\
(-0.15,0.08)\end{array}$ & $\beta=0.08(-0.03,0.19)^{c}$ & $\begin{array}{l}\beta=-0.03 \\
(-0.15,0.08)\end{array}$ & $\beta=-0.07(-0.16,0.03)^{c}$ & $\begin{array}{l}\beta=-0.03 \\
(-0.15,0.09)\end{array}$ & $\beta=-0.14(-0.23,-0.05)^{c, \$, *}$ \\
\hline $\begin{array}{l}\text { Self-efficacy - } \\
\text { succeeding }\end{array}$ & $\begin{array}{l}\beta=-0.03 \\
(-0.16,0.09)\end{array}$ & $\beta=-0.07(-0.17,0.04)^{\mathrm{c}, \$}$ & $\begin{array}{l}\beta=-0.03 \\
(-0.16,0.09)\end{array}$ & $\beta=0.05(-0.04,0.14)^{c}$ & $\begin{array}{l}\beta=-0.08 \\
(-0.20,0.05)\end{array}$ & $\beta=-0.01(-0.09,0.08)^{c}$ \\
\hline $\begin{array}{l}\text { Social influence - } \\
\text { modeling }\end{array}$ & $\begin{array}{l}\beta=0.01(-0.11 \\
0.12)^{\$}\end{array}$ & $\beta=-0.002(-0.10,0.10)^{c}$ & $\begin{array}{l}\beta=0.01(-0.11 \\
0.12)^{\$}\end{array}$ & $\beta=-0.02(-0.11,0.07)^{c}$ & $\begin{array}{l}\beta=-0.07 \\
(-0.19,0.06)\end{array}$ & $\beta=0.002(-0.08,0.09)^{c}$ \\
\hline $\begin{array}{l}\text { Social influence - } \\
\text { subjective norm }\end{array}$ & $\begin{array}{l}\beta=0.02(-0.09 \\
0.13)^{\$}\end{array}$ & $\beta=0.01(-0.10,0.12)^{c}$ & $\begin{array}{l}\beta=0.02(-0.09 \\
0.13)^{\$}\end{array}$ & $\beta=0.10(0.01,0.20)^{c, *}$ & $\begin{array}{l}\beta=0.04(-0.07 \\
0.15)\end{array}$ & $\beta=0.06(-0.04,0.15)^{c}$ \\
\hline Intention & $\begin{array}{l}\beta=0.02(-0.10 \\
0.13)^{\$}\end{array}$ & $\beta=-0.01(-0.12,0.10)^{\mathrm{d}}$ & $\begin{array}{l}\beta=0.02(-0.10 \\
0.13)^{\$}\end{array}$ & $\beta=-0.01(-0.10,0.09)^{\mathrm{d}}$ & $\begin{array}{l}\beta=-0.09 \\
(-0.20,0.03)\end{array}$ & $\beta=0.05(-0.04,0.14)^{d}$ \\
\hline Availability at home & $\begin{array}{l}\beta=0.05(-0.06 \\
0.16)\end{array}$ & $\beta=-0.13(-0.23,-0.02)^{\mathrm{e}, \$, *}$ & $\begin{array}{l}\beta=0.05(-0.06 \\
0.16)\end{array}$ & $\beta=-0.11(-0.20,-0.02)^{\mathrm{e}, *}$ & $\begin{array}{l}\beta=0.07(-0.05 \\
0.19)\end{array}$ & $\beta=-0.13(-0.21,-0.04)^{\mathrm{e}, *}$ \\
\hline Location at home & $\begin{array}{l}O R=0.99(0.40, \\
2.48)\end{array}$ & $\beta=0.02(-0.07,0.12)^{e}$ & $\begin{array}{l}O R=0.99(0.40 \\
2.48)\end{array}$ & $\beta=-0.02(-0.10,0.06)^{\mathrm{e}}$ & $\begin{array}{l}O R=0.52(0.20 \\
1.40)\end{array}$ & $\beta=0.02(0.06,0.09)^{e}$ \\
\hline
\end{tabular}

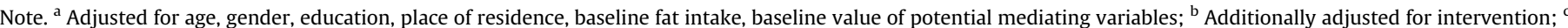

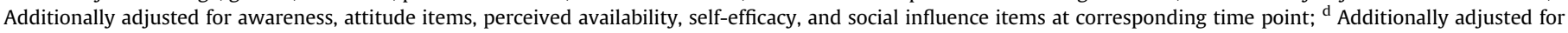
intention at corresponding time point; ${ }^{\mathrm{e}}$ Additionally adjusted for availability at home and location at home at corresponding time point.

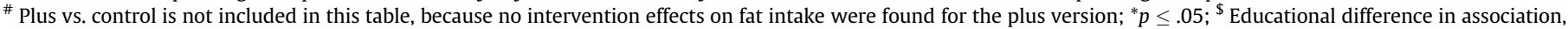
reported coefficient represents main association (not stratified).

Bold $=$ significant association at $\alpha=.05$.

fat intake). Intention was not targeted in the intervention directly, but the mediation effect of intention on fruit intake for the plus version may be the result of targeting preceding determinants, such as attitude and self-efficacy (Ajzen, 1991). No clear changes in these preceding determinants were found, but small and undetectable changes may, combined, have resulted in a change in intention.

The hypothesis that the effects of the plus version on fruit and high-energy snack intake were mediated by the targeted environmental-level factors was not clearly supported. For fruit intake, changes in the availability of fruit at home mediated the medium-term intervention effect of the plus version, but no mediation was found for high-energy snack intake. It may be that the feedback on options for modifying the availability and accessibility of foods at home was easier to integrate in daily life for fruit than for high-energy snacks. The finding that the availability of high-energy snacks mediated the effects of the basic version (among lower-educated people) was unexpected, because this determinant was not explicitly targeted in this version. However, the basic version did provide some general information on not having too many snacks at home, which could have resulted in a decrease in the availability at home. Targeting environmental perceptions by providing objective information on availability and prices of food products was a novelty in Web-based computertailored nutrition education interventions, but the results of this study indicate that the intervention did not change environmental perceptions. This may be due to the fact that the perceptions of price and availability were already quite positive in this study population and, consequently, probably no changes could have been expected. These positive perceptions may be a result of measuring general perceptions of a food group, whereas there are a large variety of products within each food group for which perceptions may differ. In addition, such a general measure may have not been sensitive enough to detect changes in the perceptions of specific products within each food group. Due to the large variety of products, it is also difficult and complex to target environmental perceptions and it may be that the way it was done in this intervention was not strong or intensive enough. Based on this first explorative study it cannot be clearly stated whether and which of the environmental-level factors account for the effects of the plus version on fruit and high-energy snack intake. Therefore, more research is needed, such as examining the separate and combined environmental-level factors in small-scale, more controlled studies and by assessing more detailed perceptions. In addition, research should be conducted on only targeting the arrangement of the home food environment, because this was the only identified mediating variable and this environmental-level factor is most feasible to incorporate in an intervention.

Examining the mediating variables of intervention effects is important, because it can inform intervention developers about which determinants should be targeted, adapted, or omitted without compromising efficacy (Hafeman \& Schwarz, 2009). Our study, however, showed that it could be difficult to identify mediating variables. For most determinants, theoretically derived practical strategies were incorporated in the intervention, but only a few associations between the intervention and (changes in) determinants were found (path a). This is in line with multiple other studies that did not find effects of tailored interventions on some or all behavioral determinants, although these interventions were not always compared to an active control group, were not all Webbased, and were in different settings (De Bourdeaudhuij, Stevens, 
Vandelanotte, \& Brug, 2007; Jacobs et al., 2004; Kroeze et al., 2006; Neville et al., 2009; Oenema, Brug, Dijkstra, de Weerdt, \& de Vries, 2008; Portnoy, Scott-Sheldon, Johnson, \& Carey, 2008). There were some small changes in the determinants, but these were not clinically relevant. Not finding an association between the intervention and the targeted determinants may indicate that there is a need to strengthen the strategies that were incorporated in the intervention. However, there are also other explanations, such as the positive scores on most determinants at baseline, which makes it more difficult to achieve or detect changes. In addition, due to the tailoring route of the intervention, participants who already had a positive attitude and a high self-efficacy could choose not to receive feedback on attitude and self-efficacy and those who were exposed to these sections only received feedback on beliefs that were most salient for them and thus, there is a difference in feedback received by the participants. Including all participants in the same analyses may, therefore, underestimate the changes in determinants. Methodological issues may also explain the lack of associations. Firstly, in the intervention, participants received feedback on specific attitude and self-efficacy beliefs, but not all beliefs were measured in the questionnaires. Consequently, it may be that changes were induced in other beliefs than those that were measured. Secondly, the intervention was compared to an active control group that received generic nutrition information that also influenced the determinants, which makes it more difficult to identify group differences (Portnoy et al., 2008). This generic information also contained information on action planning (e.g. about the importance of formulating plans), but did not include instructions on how to formulate high-quality plans. Consequently, participants in the control group may report that they perceive to have clear plans, whereas participants in the intervention groups relate this to actual action- or coping plans and are more critical in answering the questions. Thirdly, mediating variables were measured one and four months after the two-month intervention period; however, most participants only used the intervention at the beginning of this period and for many participants the measurements may actually reflect a three or seven months postintervention assessment. Consequently, the period between intervention exposure and measurement of mediating variables may have been too long, because changes in the determinants may have disappeared and become undetectable, but may already have been translated into changes in dietary behavior. Although the targeted determinants were based on evidence and theories of important determinants for dietary behaviors, for multiple variables no association with the dietary outcome was found (path b). Not finding such associations may be due to the fact that most determinants (e.g. self-efficacy or action planning) were measured regarding a change in behavior (e.g. consuming less fat or more fruit), which may not be relevant anymore when a person has already made a change in behavior. In addition, the determinants may have not been measured optimally. Action- and coping planning, for example, were measured by questioning whether people have clear plans, but did not measure the quality of the plans that is important for behavior change (de Vet, Oenema, \& Brug, 2011).

\subsection{Limitations}

When interpreting the results of this study, some limitations should be taken into account. Firstly, our study population may have been more motivated for or interested in healthy nutrition, because intake levels of the total study sample were more favorable compared to the general Dutch population (van Rossum et al., 2011). However, only people who did not comply with dietary guidelines were included in the current analyses. Secondly, despite efforts to over-recruit low-educated participants response was selective to educational level and the percentage low-educated participants was small. Thirdly, there was a high and selective dropout. A high dropout is often reported in other Web-based computer-tailored interventions (Eysenbach, 2005; Peels et al., 2012; Schulz et al., 2014; van Genugten et al., 2012), but may influence the study results. By correcting the analyses for predictors of dropout, an attempt to minimize bias potentially caused by selective dropout was made. However, the selective sample and high and selective dropout may have decreased the external validity of the results. Therefore, the results are only generalizable to Dutch adults who are interested in healthy eating, but who can still improve dietary intake patterns. Fourthly, it is not known how much time participants spend on the intervention and, consequently, whether they processed the provided information thoroughly. Fifthly, the intervention was compared to a generic nutrition information control condition only, which may have resulted in smaller sized effects than when we would have compared the intervention to a no-information control group. Sixthly, compared to the main RCT, the risk groups in the current study consisted of a small number of participants divided over the three study groups, which may have resulted in a lack of statistical power. Seventhly, although validated questionnaires were used to measure fruit and saturated fat intake, the study relied on selfreported data. This may be less valid and more sensitive to overor under-reporting compared to more objective instruments, such as biomarkers (Kroeze, Dagnelie, Heymans, Oenema, \& Brug, 2011). In addition, the items to measure high-energy snack intake were derived from validated questionnaires and used in previous studies (e.g. (Ezendam, Brug, Borsboom, van Empelen, \& Oenema, 2014; van Genugten et al., 2012)), but validity and reliability of these items to measure the amount of snacks eaten per day are not known and these results should therefore be interpreted with caution. Lastly, most potential mediating variables were measured with a small number of items. In addition, new questions were developed for environmental-level factors; for these items, validity and reliability are unknown.

\subsection{Conclusion and practical implications}

The results of this study did not show a consistent pattern of mediating variables of the effects of two versions of a Web-based computer-tailored nutrition education intervention on fruit, highenergy snack, and saturated fat intake. Some indications were found that intention and the availability of food products at home mediated intervention effects. Among high-educated people attitude and subjective norm were additionally identified as mediating variables. However, the mediating variables differed per dietary outcome. Besides considerations regarding the measurements, identifying mediating variables in computer-tailored interventions may be difficult because the feedback is tailored and only addresses the relevant determinants and, therefore, differs between participants.

\section{Conflict of interest}

Hein de Vries is the scientific director of Vision2Health, a company that licenses evidence-based, innovative, computer-tailored health communication tools. The other authors declare that they have no competing interests.

\section{Funding source}

The study was funded by ZonMw, the Netherlands Organisation for Health Research and Development (grant number: 200110021). The funding source had no role in study design, collection, analysis 
and interpretation of the data, writing of the report or in the decision to submit the article for publication.

\section{Acknowledgments}

We would like to thank Karin Hummel for her important role in the evaluation study.

\section{Appendix A. Supplementary data}

Supplementary data related to this article can be found at http:// dx.doi.org/10.1016/j.appet.2015.12.013.

\section{References}

Abraham, C., \& Michie, S. (2008). A taxonomy of behavior change techniques used in interventions. Health Psychology, 27(3), 379-387. http://dx.doi.org/10.1037/ 0278-6133.27.3.379.

Ajzen, I. (1991). The theory of planned behavior. Organizational Behavior and Human Decision Processes, 50, 179-211. http://dx.doi.org/10.1016/0749-5978(91)90020 T.

Anderson, E. S., Winett, R. A., Wojcik, J. R., Winett, S. G., \& Bowden, T. (2001) A computerized social cognitive intervention for nutrition behavior: direct and mediated effects on fat, fiber, fruits, and vegetables, self-efficacy, and outcome expectations among food shoppers. Annals of Behavioral Medicine, 23(2), 88-100.

van Assema, P., Brug, J., Ronda, G., \& Steenhuis, I. (2001). The relative validity of a short Dutch questionnaire as a means to categorize adults and adolescents to total and saturated fat intake. Journal of Human Nutrition and Dietetics, 14 , 377-390. http://dx.doi.org/10.1046/j.1365-277X.2001.00310.x.

van Assema, P., Brug, J., Ronda, G., Steenhuis, I., \& Oenema, A. (2002). A short dutch questionnaire to measure fruit and vegetable intake: relative validity among adults and adolescents. Nutrition Health, 16(2), 85-106. http://dx.doi.org/ $10.1177 / 026010600201600203$.

Ball, K., Crawford, D., \& Mishra, G. (2006). Socio-economic inequalities in women's fruit and vegetable intakes: a multilevel study of individual, social and environmental mediators. Public Health Nutrition, 9(5), 623-630. http://dx.doi.org 10.1079/PHN2005897.

Bartholomew, L. K., Parcel, G. S., Kok, G., Gottlieb, N. H., \& Fernández, M. E. (2011) Planning health promotion programs: an intervention mapping approach (2nd ed.). San Francisco: Jossey-Bass.

Bogers, R. P., van Assema, P., Kester, A. D. M., Westerterp, K. R., \& Dagnelie, P. C. (2004). Reproducibility, validity, and responsiveness to change of a short questionnaire for measuring fruit and vegetable intake. American Journal of Epidemiology, 159(9), 900-909. http://dx.doi.org/10.1093/aje/kwh123.

Broekhuizen, K., Kroeze, W., van Poppel, M. N. M., Oenema, A., \& Brug, J. (2012) A systematic review of randomized controlled trials on the effectiveness of computer-tailored physical activity and dietary behavior promotion programs: an update. Annals of Behavioral Medicine, 44(2), 259-286. http://dx.doi.org/ 10.1007/s12160-012-9384-3.

Brug, J., \& van Assema, P. (2000). Differences in use and impact of computer-tailored dietary fat-feedback according to stage of change and education. Appetite, 34(3), 285-293. http://dx.doi.org/10.1006/appe.2000.0322.

Cutler, D. M., \& Lleras-Muney, A. (2010). Understanding differences in health behaviors by education. Journal of Health Economics, 29(1), 1-28. http://dx.doi.org 10.1016/j.jhealeco.2009.10.003.

De Bourdeaudhuij, I., Stevens, V., Vandelanotte, C., \& Brug, J. (2007). Evaluation of an interactive computer-tailored nutrition intervention in a real-life setting. Annals of Behavioral Medicine, 33(1), 39-48.

Eysenbach, G. (2005). The law of attrition. Journal of Medical Internet Research, 7(1), e11. http://dx.doi.org/10.2196/jmir.7.1.e11.

Ezendam, N. P. M., Brug, J., Borsboom, G., van Empelen, P., \& Oenema, A. (2014) Differential effects of the computer-tailored FATaintPHAT programme on dietary behaviours according to sociodemographic, cognitive and home environmental factors. Public Health Nutrition, 17(2), 431-439. http://dx.doi.org/ 10.1017/S1368980012005344.

Field, A. (2009). Exploring assumptions. In A. Field (Ed.), Discovering statistics using SPSS (3th ed., pp. 131-165). London: SAGE Publications.

van Genugten, L., van Empelen, P., Boon, B., Borsboom, G., Visscher, T., \& Oenema, A (2012). Results from an online computer-tailored weight management intervention for overweight adults: randomized controlled trial. Journal of Medica Internet Research, 14(2), e44. http://dx.doi.org/10.2196/jmir.1901.

George, D., \& Mallery, P. (2005). SPSS for windows step-by-step: a simple guide and reference, 13.0 update (6th ed.). Boston: Allyn \& Bacon.

Gollwitzer, P. M., \& Sheeran, P. (2006). Implementation intentions and goa achievement: a meta-analysis of effects and processes. Advances in Experimental Social Psychology, 38, 69-119. http://dx.doi.org/10.1016/S00652601(06)38002-1.

GroentenFruit Bureau (Dutch Vegetable and Fruit Bureau). Alles over groente en fruit (Everything about vegetables and fruit) Retrieved 10-05-2014, from http:/ www.groentenenfruit.nl.

Hafeman, D. M., \& Schwarz, S. (2009). Opening the black box: a motivation for the assessment of mediation. International Journal of Epidemiology, 38, 838-845. http://dx.doi.org/10.1093/ije/dyn372.

Inglis, V., Ball, K., \& Crawford, D. (2008). Socioeconomic variations in women's diets: what is the role of perceptions of the local food environment? Journal of Epidemiology and Community Health, 62, 191-197. http://dx.doi.org/10.1136/ jech.2006.059253.

Jacobs, A. D., Ammerman, A. S., Ennett, S. T., Campbell, M. K., Tawney, K. W., Aytur, S. A., et al. (2004). Effects of a tailored follow-up intervention on health behaviors, beliefs, and attitudes. Journal of Women's Health, 13(5), 557-568.

Karoly, P. (1993). Mechanisms of self-regulation: a systems view. Annual Review of Psychology, 44, 23-52. http://dx.doi.org/10.1146/annurev.ps.44.020193.000323.

Keij, I. (2000). Standaarddefinitie allochtonen [standard definition immigrants]. In Hoe doet het CBS dat nou? (How does Statistics Netherlands do this?) (pp. 24-25). Voorburg: Centraal Bureau voor de Statistiek (Statistics Netherlands).

Kok, G., Lechner, L., Meertens, R., \& Brug, J. (2012). Theorieën en methodieken van verandering (Theories and methodologies of change). In J. Brug, P. van Assema, \& L. Lechner (Eds.), Gezondheidsvoorlichting en Gedragsverandering: Een planmatige Aanpak (Health Education and behavioral change: A systematic Approach) (8th ed.). Assen: Van Gorcum.

Konttinen, H., Sarlio-Lähteenkorva, S., Silventoinen, K., Männistö, S., \& Haukkala, A. (2012). Socio-economic disparities in the consumption of vegetables, fruit and energy-dense foods: the role of motive priorities. Public Health Nutrition, 16(5), 873-882. http://dx.doi.org/10.1017/S1368980012003540.

Krebs, P., Prochaska, J. O., \& Rossi, J. S. (2010). A meta-analysis of computer-tailored interventions for health behavior change. Preventive Medicine, 51, 214-221. http://dx.doi.org/10.1016/j.ypmed.2010.06.004.

Kroeze, W., Dagnelie, P. C., Heymans, M. W., Oenema, A., \& Brug, J. (2011). Biomarker evaluation does not confirm efficacy of computer-tailored nutrition education. Journal of Nutrition Education and Behavior, 43(5), 323-330. http://dx.doi.org/ 10.1016/j.jneb.2010.09.009.

Kroeze, W., Oenema, A., Campbell, M., \& Brug, J. (2008). The efficacy of web-based and print-delivered computer-tailored interventions to reduce fat intake: results of a randomized, controlled trial. Journal of Nutrition Education and Behavior, 40, 226-236. http://dx.doi.org/10.1016/j.jneb.2007.09.008.

Kroeze, W., Werkman, A., \& Brug, J. (2006). A systematic review of randomized trials on the effectiveness of computer-tailored education on physical activity and dietary behaviors. Annals of Behavioral Medicine, 31(3), 205-223. http:// dx.doi.org/10.1207/s15324796abm3103_2.

Lustria, M. L., Cortese, J., Noar, S. M., \& Glueckauf, R. L. (2009). Computer-tailored health interventions delivered over the web: review and analysis of key components. Patient Education and Counseling, 74, 156-173.

Luszczynska, A., Tryburcy, M., \& Schwarzer, R. (2007). Improving fruit and vegetable consumption: a self-efficacy intervention compared with a combined selfefficacy and planning intervention. Health Education Research, 22(5), 630-638. http://dx.doi.org/10.1093/her/cyl133.

MacKinnon, D. P., Lockwood, C. M., Hoffman, J. M., West, S. G., \& Sheets, V. (2002) A comparison of methods to test mediation and other intervening variable effects. Psychological Methods, 7(1), 83-104. http://dx.doi.org/10.1037/1082989X.7.1.83.

Maes, S., \& Gebhardt, W. (2000). Self-regulation and health behavior: the health behavior goal model. In P. R. P. M. Boekaerts, \& M. Zeidner (Eds.), Handbook of self-regulation (pp. 343-368). San Diego: Academic Press.

Maes, S., \& Karoly, P. (2005). Self-regulation assessment and intervention in physical health and illness: a review. Applied Psychology: An International Review, 54(2), 267-299. http://dx.doi.org/10.1002/14651858.CD007617.pub2.

Mento, A. J., Steel, R. P., \& Karren, R. J. (1987). A meta-analytic study of the effects of goal setting on task performance: 1966-1984. Organizational Behavior and Human Decision Processes, 39(1), 52-83. http://dx.doi.org/10.1016/07495978(87)90045-8.

Michie, S., Abraham, C., Whittington, C., McAteer, J., \& Gupta, S. (2009). Effective techniques in healthy eating and physical activity interventions: a metaregression. Health Psychology, 28(6), 690-701. http://dx.doi.org/10.1037/ a0016136.

Neubert, M. J. (1998). The value of feedback and goal setting over goal setting alone and potential moderators of this effect: a meta-analysis. Human Performance, 11(4), 321-335. http://dx.doi.org/10.1207/s15327043hup1104_2.

Neville, L. M., O'Hara, B., \& Milat, A. J. (2009). Computer-tailored dietary behaviour change interventions: a systematic review. Health Education Research, 24(4), 699-720. http://dx.doi.org/10.1093/her/cyp006.

Noar, S. M., Benac, C. N., \& Harris, M. S. (2007). Does tailoring matter? meta-analytic review of tailored print health behavior change interventions. Psychological Bulletin, 133(4), 673-693. http://dx.doi.org/10.1037/0033-2909.133.4.673.

Oenema, A., Brug, J., Dijkstra, A., de Weerdt, I., \& de Vries, H. (2008). Efficacy and use of an internet-delivered computer-tailored lifestyle intervention, targeting saturated fat intake, physical activity and smoking cessation: a randomized controlled trial. Annals of Behavioral Medicine, 35, 125-135. http://dx.doi.org/ $10.1007 / \mathrm{s} 12160-008-9023-1$

Oenema, A., Tan, F., \& Brug, J. (2005). Short-term efficacy of a web-based computertailored nutrition intervention: main effects and mediators. Annals of Behavioral Medicine, 29(1), 54-63. http://dx.doi.org/10.1207/s15324796abm2901_8.

Peels, D. A., Bolman, C., Golsteijn, R. H. J., de Vries, H., Mudde, A. N., van Stralen, et al. (2012). Differences in reach and attrition between web-based and printdelivered tailored interventions among adults over 50 years of age: clustered 
randomized trial. Journal of Medical Internet Research, 14(6), e179. http:// dx.doi.org/10.2196/jmir.2229.

Portnoy, D. B., Scott-Sheldon, L. A. J., Johnson, B. T., \& Carey, M. P. (2008). Computerdelivered interventions for health promotion and behavioral risk reduction: a meta-analysis of 75 randomized controlled trials, 1988-2007. Preventive Medicine, 47, 3-16. http://dx.doi.org/10.1016/j.ypmed.2008.02.014.

van Rossum, C. T. M., Fransen, H. P., Verkaik-Kloosterman, J., BuurmaRethans, E. J. M., \& Ocké, M. C. (2011). Dutch national food consumption survey 2007-2010: diet of children and adults aged 7 to 69 years (RIVM-Report 350050006/2011). Bilthoven: RIVM.

Schulz, D. N., Kremers, S. P. J., Vandelanotte, C., van Adrichem, M. J. G., Schneider, F., Candel, M. J. J. M., et al. (2014). Effects of a web-based tailored multiple-lifestyle intervention for adults: a two-year randomized controlled trial comparing sequential and simultaneous delivery modes. Journal of Medical Internet Research, 16(1), e26. http://dx.doi.org/10.2196/jmir.3094.

Sniehotta, F. F., Schwarzer, R., Scholz, U., \& Schüz, B. (2005). Action planning and coping planning for long-term lifestyle change: theory and assessment. European Journal of Social Psychology, 35, 565-576. http://dx.doi.org/10.1002/ ejsp.258.

Springvloet, L., Lechner, L., de Vries, H., Candel, M. J. J. M., \& Oenema, A. (2015) Short- and medium-term efficacy of a web-based computer-tailored nutrition education intervention for adults including cognitive and environmental feedback: randomized controlled trial. Journal of Medical Internet Research, 17(1), e23. http://dx.doi.org/10.2196/jmir.3837.

Springvloet, L., Lechner, L., \& Oenema, A. (2014). Planned development and evaluation protocol of two versions of a web-based computer-tailored nutrition education intervention aimed at adults, including cognitive and environmental feedback. BMC Public Health, 14, 47. http://dx.doi.org/10.1186/1471-2458-14-47. van Stralen, M. M., de Vries, H., Mudde, A. N., Bolman, C., \& Lechner, L. (2009). The working mechanisms of an environmentally tailored physical activity intervention for older adults: a randomized controlled trial. International Journal of Behavioral Nutrition and Physical Activity, 6, 83. http://dx.doi.org/10.1186 1479-5868-6-83.

Strecher, V. J., Seijts, G. H., Kok, G. J., Latham, G. P., Glasgow, R., DeVellis, B., et al (1995). Goal setting as a strategy for health behavior change. Health Education \& Behavior, 22(2), 190-200. http://dx.doi.org/10.1177/109019819502200207.

Verweij, A. (2008). Onderwijsdeelname: Indeling opleidingsniveau [Education participation: Classification level of education]. In Volksgezondheid Toekomst Verkenning, Nationaal Kompas Volksgezondheid. Bilthoven: RIVM.

de Vet, E., Oenema, A., \& Brug, J. (2011). More or better: do the number and specificity of implementation intentions matter in increasing physical activity? Psychology of Sport and Exercise, 12, 471-477.

Voedingscentrum (Netherlands Nutrition Centre). Voedingscentrum (Netherlands nutrition Centre). Retrieved 10-05-2014, from http://www.voedingscentrum.nl/ nl.aspx.

Voedingscentrum (Netherlands Nutrition Centre). (2011). Richtlijnen voedselkeuze (guidelines food choice). Retrieved 06-06-2013, from http://www. voedingscentrum.nl/Assets/Uploads/voedingscentrum/Documents/ Professionals/Voedselvoorlichting/01.

RichtlijnenvoedselkeuzeVoedingscentrum.pdf.

Weinstein, N. D. (1988). The precaution adoption process. Health Psychology, 7(4), 355-386. http://dx.doi.org/10.1037/0278-6133.7.4.355.

Weinstein, N. D. Sandman, P. M., \& Blalock, S. J. (2008). The precaution adoption process model. In K. Glanz, B. K. Rimer, \& K. Viswanath (Eds.), Health behavior and health education: theory, research and practice (pp. 123-148). San Francisco: Jossey-Bass.

Winett, R. A., Anderson, E. S., Wojcik, J. R., Winett, S. G., \& Bowden, T. (2007). Guide to health: nutrition and physical activity outcomes of a group-randomized trial of an internet-based intervention in churches. Annals of Behavioral Medicine, 33(3), 251-261. http://dx.doi.org/10.1007/BF02879907. 